Document downloaded from:

http://hdl.handle.net/10251/66301

This paper must be cited as:

Pastor Soriano, JV.; Payri, R.; García Oliver, JM.; Briceño Sanchez, FJ. (2013). Schlieren Methodology for the Analysis of Transient Diesel Flame Evolution. SAE International Journal of Engines. 6(3):1661-1676. doi:10.4271/2013-24-0041.

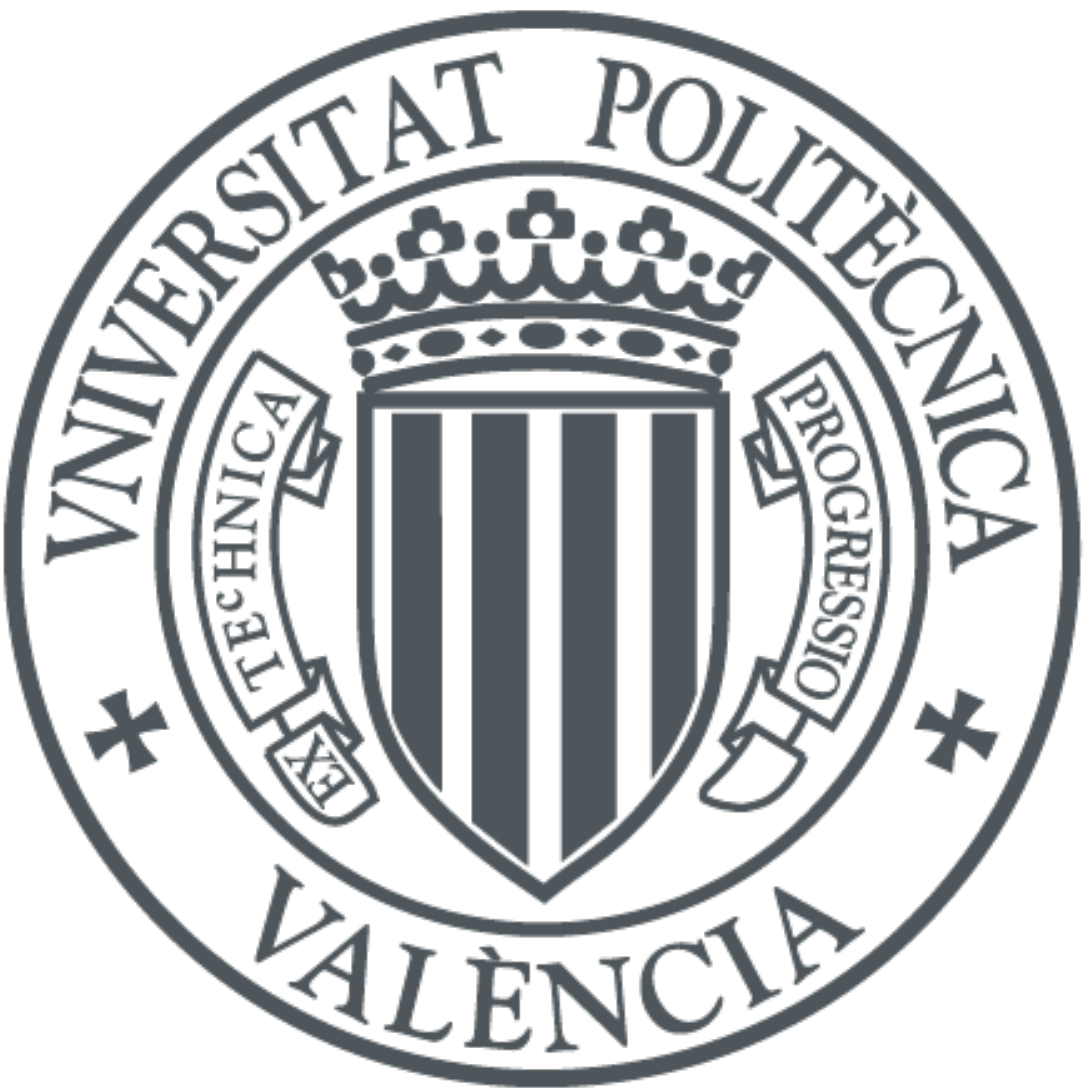

The final publication is available at

http://dx.doi.org/10.4271/2013-24-0041

Copyright SAE International

Additional Information 


\title{
Schlieren Methodology for the Analysis of Transient Diesel Flame Evolution
}

\author{
Author, co-author (Do NOT enter this information. It will be pulled from participant tab \\ in MyTechZone)
}

Affiliation (Do NOT enter this information. It will be pulled from participant tab in MyTechZone)

\begin{abstract}
$\underline{\text { ABSTRACT }}$
Schlieren/shadowgraphy has been adopted in the combustion research as a standard technique for tip penetration analysis of sprays under diesel-like engine conditions. When dealing with schlieren images of reacting sprays, the combustion process and the subsequent light emission from the soot within the flame have revealed both limitations as well as considerations that deserve further investigation. Seeking for answers to such concerns, the current work reports an experimental study with this imaging technique where, besides spatial filtering at the Fourier plane, both short exposure time and chromatic filtering were performed to improve the resulting schlieren image, as well as the reliability of the subsequent tip penetration measurement. The proposed methodology has reduced uncertainties caused by artificial pixel saturation (blooming). Additionally, an algorithm to calculate Lift-off length from schlieren images has been developed and compared to the more conventional $\mathrm{OH}^{*}$ imaging technique.
\end{abstract}

By means of the improved setup, the analysis of transient diesel flame has been performed throughout the ignition and early combustion phases. When compared to a non-reacting vaporizing spray, the temporal evolution of the reacting case departs from the inert one at the start of combustion, when expansion in both axial (i.e. spray tip increase) and radial direction are observed. After that, the tip penetration progressively decreases on a clear transient period where the flow tries to re-organize itself in response to the induced reaction zone. Eventually, the spray undergoes an acceleration period where the reacting spray tip progresses above the nonreacting one. A parametric study has been conducted for three injection pressure levels to investigate the influence of this parameter upon transient flame evolution.

\section{INTRODUCTION}

The progressively more restrictive regulation on exhaust emissions is the main motivation that drives researchers when characterizing the pollutant formation mechanisms within
Diesel flames. In this sense, fuel-air mixing process within Diesel spray plays a fundamental role and therefore, the investigation on such mixing mechanisms and their impact on engine performance have been pivotal in recent years [1-4].

In that sense, the use of optical techniques provided both qualitative and also quantitative data about mixing processes in terms of the fuel-air composition within the spray. Regarding local quantification under non-reacting conditions, techniques like Laser Induced Fluorescence [5-7] or Light Absorption Scattering [8,9] can provide reliable fuel-air equivalence ratios. However, the main drawback of such techniques is the difficulty in obtaining a time-resolved description of a single injection process because of the weak signals and the need of intensified cameras (commonly with low recording frequency); not to mention inherent difficulties such as signal quenching [7] and also the calibration needed to convert pixels counts into final fuel-air equivalence ratio.

On the other hand, schlieren/shadowgraphy technique can provide a single-injection time-resolved description of spray tip penetration and cone angle [10-12], which are indirect parameters of how the fuel-air mixing process develops. Based upon the same measurement principle, namely the steering of light rays when going through a medium where density gradients exist, the only difference between both techniques is the use of a cut-off at the Fourier plane for schlieren, which enhances contrast but may also induce some loss of information, whereas no cut-off is used for shadowgraphy. Such measurements have helped validate penetration scaling law models [13] as well as mixing-controlled 1D spray models derived from gas-jet theory [14,15] and even CFD models [16]. The widespread use of such measurements for validation purposes underlines the potential of schlieren when investigating Diesel sprays [17].

Schlieren/shadowgraphy visualization can also be applied to the study of the reacting phases of diesel spray evolution. The measurement principle indicates that combustion-induced drop in density should be captured by the technique, and this should enable macroscopic characterization of the diesel flame.

Page 1 of 18 
Compared to direct flame visualization, which is mainly focused on the chemically active parts of the Diesel flame, schlieren should also be sensitive to the presence of hot combustion products, even if they are outside of the reaction front. Few studies can be found in the literature $[17,18]$ that make use of schlieren/shadowgraphy visualization for the analysis of reacting spray. Furthermore, when looking into the described trends of reacting tip penetration compared to the inert one, results are somewhat non-consistent. By means of shadowgraphy, Picket et al. in [19] have reported reacting spray results that penetrated slightly faster than the inert one. Moreover, the same author in [20] using the same optical setup but adding a schlieren cut-off (which are not used in shadowgraphy imaging) reported that the reacting spray progressed slightly more slowly than the inert case. Additionally, they showed that the spray seems to disappear during the cool-flame period. In more recent studies reported at Engine Combustion Network (ECN) workshops, schlieren was performed at different facilities with identical test conditions and very similar optical setups [12]. Results have shown that the measured reacting penetration tendencies varied among different laboratories. Authors argued that differences in penetrations were associated to background (hot/cold ambient gases) schlieren sensitivity as well as to the soot luminosity that interfered on the processing steps.

Besides ambient conditions, the optical set-up and the schlieren/shadowgraphy sensitivity seem to affect the vapor fuel-related information that is eventually displayed in a schlieren image. Furthermore, there are cumbersome issues when digital analysis is applied to the resulting images that include: artificial pixel saturation, i.e. blooming phenomenon [21] or unusual histogram distributions [22], which limit or at least introduce uncertainty when systematic measurements are performed. Therefore, when considering the discrepancies among configurations from different authors (schlieren sensitivity, interfering soot luminosity and processing tools), it might seem reasonable that the corresponding reacting tip penetration trends may not fully agree [17-20].

After the previous state-of-art description, the present work tries to contribute to the description of the reacting Diesel spray by making use of schlieren visualization. The main goal is to make a comparison of spray tip penetration evolution when shifting from inert to reacting conditions. According to the last two paragraphs, one of the main guidelines of this investigation is to try to develop a schlieren optical set-up that minimizes uncertainties associated to the application of the technique to Diesel sprays by removing soot luminosity, which in turn improves digital analysis of the images and the quantitative evaluation of the penetration behavior.

In addition to these issues there are indications, yet not exploited, about the potential of schlieren images to provide measurements of lift-off length when a schlieren contour is overlaid on a simultaneous $\mathrm{OH}^{*}$ chemiluminescence image [20]. Therefore, a purpose-developed routine for schlieren liftoff measurements was implemented based on high-speed

Page 2 of 18 recording, which also adds the possibility of measuring a time resolved lift-off length, together with other common spray parameter extracted from schlieren images (penetration, spray angle, SOC, etc.). The methodology was tested and compared to simultaneous $\mathrm{OH}$ chemiluminescence measurements performed in a Constant-Pressure Flow (CPF) vessel.

In this paper, the above introduced topics are discussed as follows: First the experimental apparatus used on this investigation is presented. In the subsequent diagnostics and measurements section, the optical set-up and the implication of removing soot luminosity are addressed, together with the final results obtained from digital analysis. Furthermore, the definitions and steps followed on the schlieren lift-off routine are discussed, as well as the $\mathrm{OH}$ image analysis procedures. The results section summarizes the main outputs of the proposed methodology. First, the significance of schlierenderived Lift-off Length measurements is discussed compared to $\mathrm{OH}^{*}$-derived one. Reacting spray penetration is compared to the inert one, and the effect of increasing the injection pressure is addressed. Lastly, the summary/conclusions section contains the most important findings of the present work.

\section{EXPERIMENTAL APPARATUS}

TDC engine-like thermodynamic conditions were simulated on the High-pressure\&High-Temperature test rig shown in Figure 1. This constant-pressure flow (CPF) vessel is filled with gases that can be pressurized and heated up to $15 \mathrm{MPa}$ and $1000 \mathrm{~K}$, respectively. Electrical resistances provide the energy to heat up the gas to a target temperature selected by the user on a PID control, which also controls the pressure level inside the vessel. The double layer wall configuration of the vessel enables improvement on homogeneity of the temperature distribution inside the chamber. Heat transfer losses to the room ambient have been limited by (i) an isolating material that fills the space between the surfaces in contact with the gas and the ambient, and (ii) a secondary electrical resistance that heats up the outer layer of the combustion vessel.

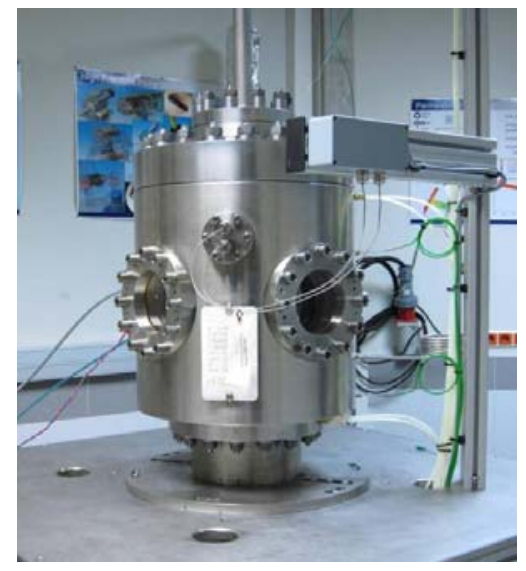

Figure 1. High Pressure-High Temperature test rig 
The facility can be operated in either open or closed loop. In the former case, dry air is supplied by a volumetric compressor. In closed loop configuration, a $\mathrm{N}_{2} / \mathrm{O}_{2}$ mixture at controlled concentration is continuously re-circulated. Downstream the combustion vessel, a cyclonic filter removes non-vaporized fuel from the gas flow, avoiding ambient saturation with fuel. The gas velocity across the chamber has been estimated to be minor compared to the spray velocities even at far distances from the spray tip, with approximate values of $0.2 \mathrm{~m} / \mathrm{s}$ and $0.4 \mathrm{~m} / \mathrm{s}$. As a consequence, the shot-toshot spray dispersion is reduced when compared to optical engines and rapid compression machines because of the steady flow configuration. Since high temperatures are continuously flowing around the injector tip, a water coolant circuit has been drilled in the injector port to maintain the user selected constant and safe temperature on the injector body (363 K on spray-A studies). An independent electronic system controls injection frequency during the experiments, being 0.5 $\mathrm{Hz}$ for this investigation.

Four orthogonally drilled ports provide access to the combustion chamber. The first one is occupied by the injector port and the cooling system for the injector body. The other three accesses are equipped with round quartz windows $(128 \mathrm{~mm})$ in a $\mathrm{T}$-shaped path providing both perpendicular access and frontal view for spray analysis of single-hole nozzles and multiple-hole nozzles, respectively.

\section{OPTICAL DIAGNOSTICS AND MEASUREMENTS}

\section{$\underline{\text { Schlieren Visualization and Optical Set-up }}$}

The shadowgraph effect is a common phenomenon found in some everyday life situations. Based upon the variation of the refractive index (n) of a target gas/liquid, the shadowgraph effect produces a deviation of light beams from the original path creating a shadow when they travel through a nonuniform medium towards an observer. The relationship between refractive index and density, which is a more useful variable in terms of spray studies, has been mathematically described in [23] trough Equation 1, where the refractive index is expressed in terms of the Gladstone-dale number $(\mathrm{k})$ and the density of the gas/liquid $(\rho)$.

$$
\boldsymbol{n}=\boldsymbol{k} \cdot \boldsymbol{\rho}+1
$$

The application of a shadowgraph to measure vapor phase penetration requires a detailed control and knowledge about the propagation of light through the medium (e.g. engine combustion chambers [24] or vessels [13]). The simplest scenario for the shadowgraph visualization is that of creating a parallel orientated light array from a point light source using a lens as observed on the Figure 2a. On the A-A plane, one can observe different levels of light intensity due to the deviation with respect to the original propagation direction for each of the effects considered in the plot.

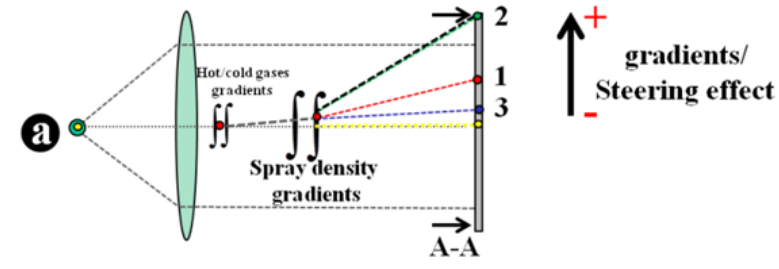

(b
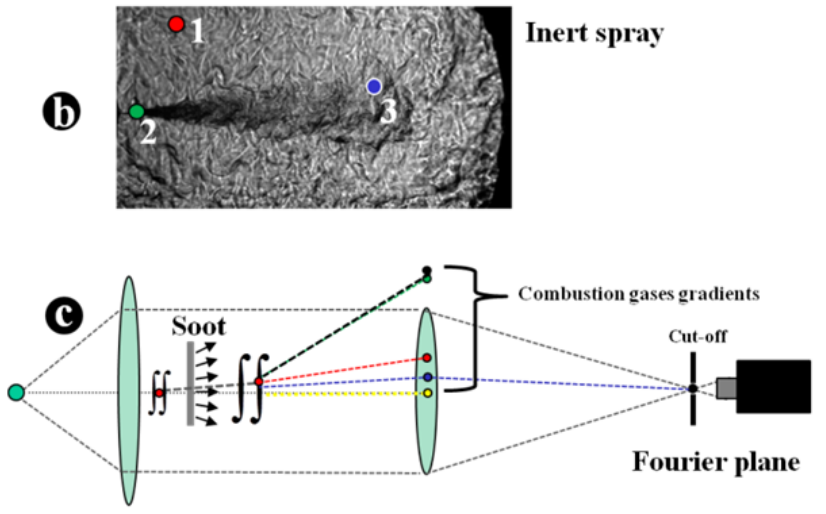

(d)

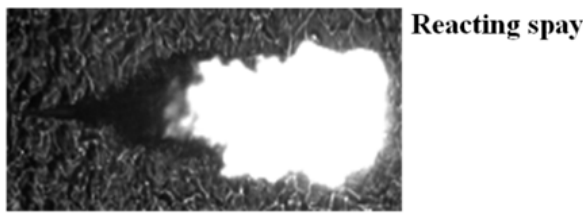

e

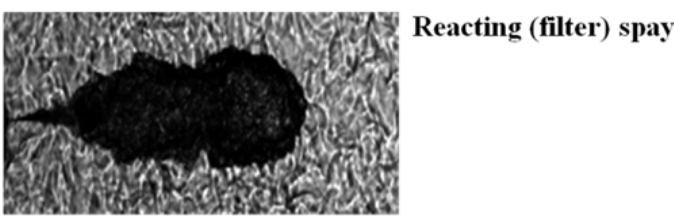

Figure 2. Sketch of the schlieren phenomenology for Diesel spray studies

Starting with at a theoretically unperturbed ray that does not interact with the spray (label "1" in Figure 2b), once it transits through a non-uniform medium, it suffers a deviation or steering process as a consequence of local non-uniformities that results in a shift (red spot upon the A-A plane) compared to the original path (yellow spot) in Figure 2a. When considering light beams that interact with the fuel spray, variable fuel-air composition (and hence refractive index) can be expected. The deviation magnitude depends on the local fuel-air mixture density gradients. Steepest gradients can be found inside the liquid core and close to the nozzle (label " 2 " in Figure 2b), whereas lowest gradients occur far away from the nozzle (label "3" in Figure 2b). Accordingly, a deviation range can be expected according to the location within the spray. Notice that spray mixture gradients could match the steering effect induced by hot and cold gases (label " 1 " in Figure $2 \boldsymbol{b}$ ). On the other hand, lean mixtures (equivalence ratio near zero) could mimic the path of unperturbed rays (zero deviation) as long as the ray is re-oriented. Such rays would avoid the schlieren cut-off on the Fourier plane, and would go back to the original unperturbed path (yellow spot) as depicted in Figure 2c. 
As a consequence of heat release, the increased temperature inside the flame core creates a density gradient which is directly related to a steering originated by combustion gases in Figure $2 \boldsymbol{e}$ (filtering will be discuss on latter sections). It is difficult to predict how strong steering by hot combustion gases is. However, it can be hypothesized that such combustion-induced steering can be similar to liquid deviation, since the dark levels in Figure $2 \boldsymbol{e}$ are quite similar to the ones in label "2" in Figure $2 \boldsymbol{b}$.

The presence of soot within the flame results in the emission of light that does not perturb the induced schlieren effect as seen in Figure $2 \boldsymbol{d}$ along the spray. However, soot radiation can be problematic when inducing pixel contamination (blooming phenomenon [20]) in high intensity zones. As a pixel reaches the maximum dynamic range of the camera, it may excite surrounding pixels. Therefore, the background could be part of the resulting spray zone detected by the processing routine. As a consequence, over-predicted penetration results could be expected.

The needs of confining all of this information into a small camera sensor by means of a lens result in additional issues. As shown in Figure 2e, the finite size of collecting lenses as well as the distance between the lens and the schlieren location could limit the capability to have a controlled schlieren system. In this sense, Pastor et al. used systematic analysis in [25] to provide better understanding of how different optical systems resulted into different images appearance and consequently a scattering in the final spray penetration measurements. They concluded on the needs of having a controlled schlieren system by: (i) adding a cut-off on the Fourier plane where all collected light (ii) minimizing the distance between the spray and the collecting lens and (iii) maximizing the camera lens size. All three issues are intended to avoid non-intended light clipping, i.e. uncontrolled schlieren effect.

The "focused single pass" schlieren setup [23] in Figure 3 helped overcome the blooming problematic as it will be discussed latter on this paper. This optical arrangement can be divided in two different sections, which are referred to as the illumination and collection sections. Upstream the spray on the illumination section, a coherent and parallel light ray array was created by placing a diffused point light source at the focal length of a parabolic mirror $(f=610 \mathrm{~mm})$. This diffused pointed source (iris clear aperture of $2 \mathrm{~mm}$ ) has been obtained by integration of the light coming out of a Xenon arc lamp through a liquid light guide and orienting the light orthogonally to the vessel. The visualization area was maximized because of the mirror diameter $(150 \mathrm{~mm})$ being larger than the optical windows $(128 \mathrm{~mm})$.

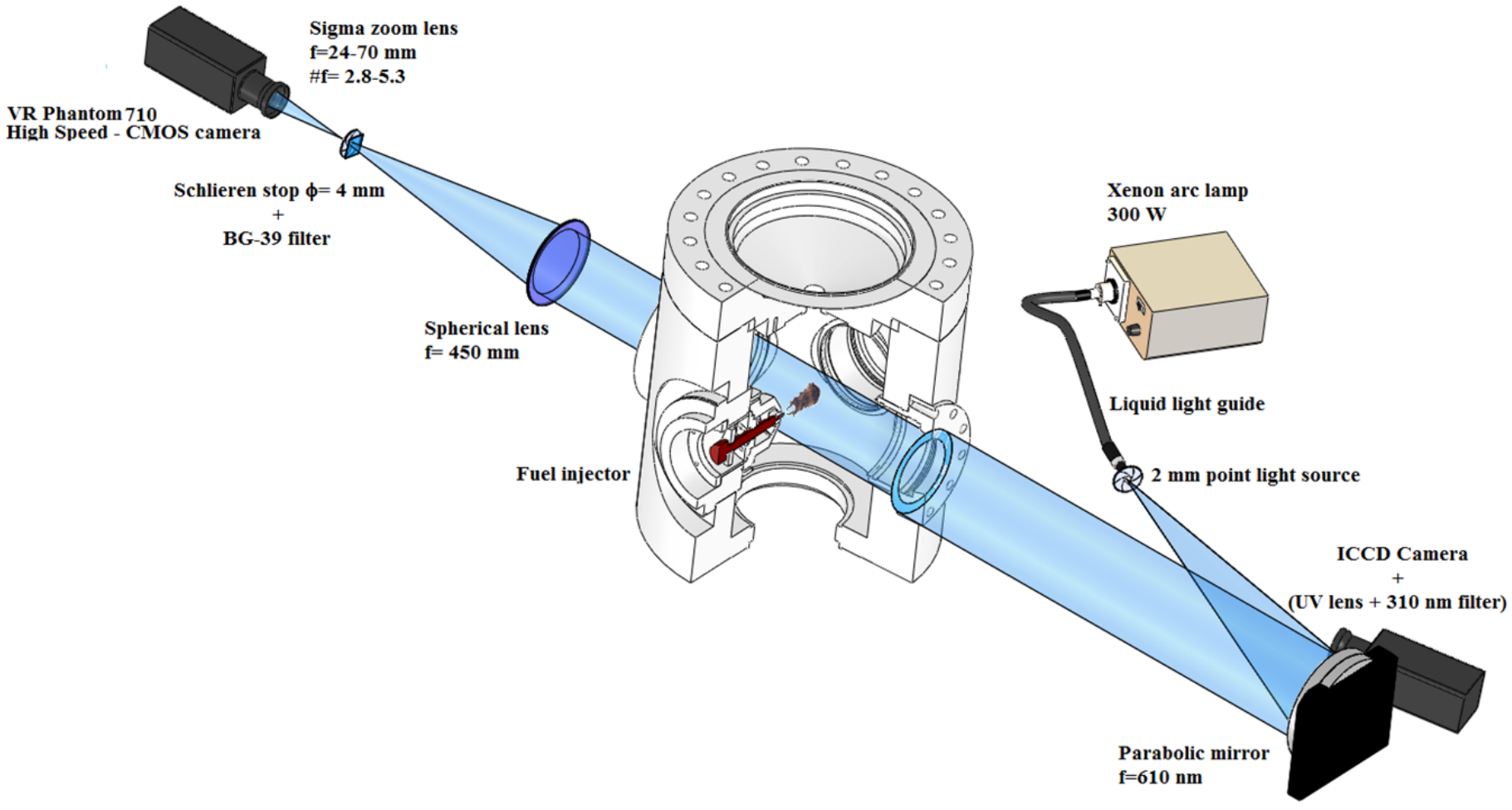

Figure 3. Schematic of the optical set-up for schlieren visualization and $\mathrm{OH}^{*}$ imaging. 
Downstream the spray on the collection section, a spherical lens is placed after the combustion vessel that concentrates the light onto the so-called Fourier plane, where a round cut-off (iris clear aperture of $4 \mathrm{~mm}$ ) was placed. The camera (Vision Research Phantom V710) is placed right after this plane together with a commercial lens that finally drives all the light beams onto the camera chip.

Settles has reported [23] some issues to be considered when using the optical configuration depicted in Figure 3. On the one hand, the theoretical point light source is far from the real 2-mm extended light source used in this investigation. Light ray parallelism on the illumination section could be uncertain because a right focusing of the parabolic mirror cannot be guaranteed all over the light source width. However, in previous work [25], Pastor et al. demonstrated that varying the width of the light source (comparison between $1 \mathrm{~mm}$ and 6 $\mathrm{mm}$ ) only affects the measuring range of the schlieren system, but neither the sensitivity, nor background illumination, nor the most important parameter, i.e. the tip penetration value. As the optical set-up in Figure 3 is similar to that found in [25], measurements in the current configuration should be accurate regardless the extended light width.

On the other hand, matching a parabolic mirror with a spherical collection lens usually causes optical aberrations. Astigmatism is the more-likely aberration in configurations such as Figure 3, due to differences on the path length along the optical centerline and the parabolic mirror periphery due to the off-axis tilt. Here, the off-axis angle of the extended light source with respect to the parabolic mirror was reduced to avoid or minimize the aberrations. In this sense, Settles indicates that Z-type arrangement is the most extended solution to overcome astigmatism, since off-axis angles are reduced to their minimum. The drawback when using such optical array in CPF vessels is the imperative far location of the parabolic collection lens, i.e. poorer collection angle ( $>$ $250.6 \mathrm{mrad}$ in [25]). Because of that, non-intended light clipping as depicted in Figure 2e (green and black lines missing the collection lens) is enhanced, and as a consequence a fully controlled schlieren effect at the cut-off plane cannot be guaranteed.

Table 1. Recording set-up for schlieren imaging and $\mathrm{OH}$ chemiluminescence.

\begin{tabular}{lcc} 
& Schlieren Camera & OH* Camera \\
\hline Frame rate $(\mathrm{fps})$ & 42000 & $1 /$ injection \\
Exposure time $(\mu \mathrm{s})$ & 0.3 & 3000 \\
Start of recording $(\mathrm{ms})$ & $0 \mathrm{ASOE}$ & $2.3 \mathrm{ASOE}$ \\
Image resolution $(\mathrm{pixel})$ & $544 \times 184$ & $512 \times 196$ \\
mm-pixel ratio & 0.297 & 0.171 \\
\hline
\end{tabular}

Table 1 shows the resulting image size and mm-pixel conversion from the schlieren optical arrangement, as well as the frame rate and exposure time set on the high-speed camera. A second imaging assembly (ICCD camera +UVlens $+310 \mathrm{~nm}$ filter in Figure 3) was placed with an incidence angle (respect to the spray axial plane) of $13^{\circ}$ degrees, to capture the $\mathrm{OH}^{*}$ chemiluminescence emitted from the flame, using the camera recording set-up also shown in Table 1.

\section{Schlieren Penetration Processing}

\section{Processing Routines}

Two processing routines were used to extract quantitative information from schlieren images. On the one hand, a purpose-developed code based on a One-Dimensional Loglikelihood Ratio Test (1D LRT) algorithm for segmentation [22] was used for spray penetration measurement. This code statistically determines a threshold digital level value to separate spray and background for every single schlieren image after subtracting a background image, which in the present study is obtained by ensemble-averaging a set of 30 images recorded before start of injection. The resulting binary image is processed with connectivity algorithms to establish the spray contour, which makes geometrical measurements feasible. The tip penetration is defined as the location of the farthest detected pixel. Initially this code was meant to analyze the liquid length derived from Diffuse Back Illumination technique (DBI), then it was extended to Mie-scattering visualization and recently, it has been shown to be adequate for double-pass schlieren image analysis [26] with relatively short spray lengths $(22.5 \mathrm{~mm})$ [24]. Detailed information of this code can be found in [22], which will be referred to in the next sections as LRT code.

On the other hand, an open code for spray penetration measurements proposed by the ECN community has been used for comparison with LRT results. This code was developed by Sandia National Laboratories group and can be found online $[27,28]$. This method tries to remove the schlieren effect of the hot ambient gases to detect the jet structure [12]. The code is based on the texture that a schlieren image has at any time instant. A derivative process is performed to the image, subtracting the two preceding images $\mathrm{I}_{\mathrm{t}-1}$ and $\mathrm{I}_{\mathrm{t}-2}$. This two-step derivative process highlights the activity zones of the schlieren image, i.e. those pixels that experiment any change because of (i) the spray motion (target measurement) or (ii) background hot-ambient gases motion. This second effect was proven to have no influence on the final result, because of the slow gas velocities on experimental apparatus like the one used on this study $(0.2-0.4 \mathrm{~m} / \mathrm{s})$. Furthermore, the high-speed frame rates (see Table 1) minimize background changes that can happen between two consecutive images. The resulting image is processed with connectivity algorithms and penetration is quantified following the procedure established in [13]. In subsequent sections, this routine will be referred to as the texture code. 

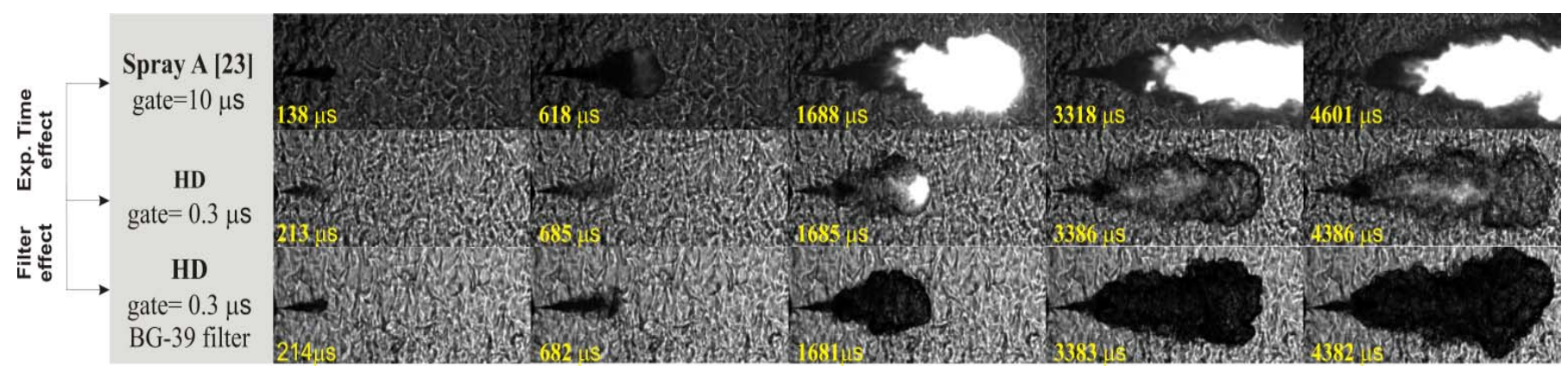

Figure 4. Schlieren representative images of the injection event for different operating conditions. The Fourier plane iris clear aperture is $4 \mathrm{~mm}$. HD conditions $T_{a i r}=826 \mathrm{~K}, \rho_{a i r}=28.4 \mathrm{Kg} / \mathrm{m}^{3}, \Delta P_{i n j}=50 \mathrm{MPa}$ and, nozzle diameter $d_{0}=82 \mu \mathrm{m}$

\section{Implications of Temporal and Chromatic Filtering on Schlieren Image Processing}

Figure 4 summarizes the effect of performing temporal and chromatic filtering with the objective of eliminating soot radiation effect. Images reported in [25] for Spray-A (top row) have been compared to those obtained in the present study under some ambient conditions with a higher density than the nominal one used in the current study. Taking into account the operating parameters, stronger soot radiation is expected at those conditions $\left(\rho_{\mathrm{air}}=28.4 \mathrm{Kg} / \mathrm{m}^{3}, \mathrm{~T}_{\mathrm{air}}=870 \mathrm{~K}, \mathrm{XO}_{2}=21 \%\right.$, fuel: $n$-heptane, $\Delta \mathrm{P}_{\text {inj }}=50 \mathrm{MPa}$ and, nozzle diameter $\mathrm{d}_{0}=82$ $\mu \mathrm{m})$ compared to spray-A ones. $\left(\rho_{\text {air }}=22.8 \mathrm{Kg} / \mathrm{m}^{3}, \mathrm{~T}_{\text {air }}=900 \mathrm{~K}\right.$, $\mathrm{XO}_{2}=15 \%$, fuel: $n$-dodecane, $\Delta \mathrm{P}_{\text {inj }}=150 \mathrm{MPa}$ and, nozzle diameter $\left.\mathrm{d}_{0}=90 \mu \mathrm{m}\right)$.

Figure 4 shows that reducing gate time from $10 \mu$ s (top set in) to $0.3 \mu$ s (middle set) results in reduced soot luminosity. The reduction in gate time has to be compensated by using high power light sources on the illumination section of the optical setup (Figure 3). Otherwise, background lighting is also proportionally reduced, and image segmentation can be cumbersome. Despite the significant reduction in gate time, remaining soot luminosity can still be observed in middle set of images in Figure 4. The image at $1685 \mu$ s After Start Of Injection (ASOI) shows high luminosity from soot at the flame tip, although luminosity decreases to lower digital levels near the end of injection at $4586 \mu$ s ASOI. Achieving a soot-free schlieren image could not be fulfilled just by shrinking the exposure time; especially if other operating conditions with more intense soot luminosity are used (e.g. larger nozzle diameter, higher air temperature, etc.). The very bottom set of images in Figure 4, shows the added effect of chromatic filtering in the Fourier plane with a BG-39 filter. According to the specifications [29], BG-39 is used as a bandpass filter, with a peak transmissivity of $88 \%$ at $513 \mathrm{~nm}$, and transmissivity is below $10 \%$ for wavelengths below $330 \mathrm{~nm}$ or above $660 \mathrm{~nm}$. This filter has been used as a compromise between suppressing long wavelengths, which helps reduce strong soot radiation that might cause blooming, and allowing

Page 6 of 18 the light source broadband radiation to reach the camera sensor to create an adequate background illumination.

With the previously described setup, no soot luminosity was observed to cause blooming on the camera sensor for the different conditions used along this study, even though some of them could maximize soot radiation within the flame (e.g. higher temperatures). Therefore, the time-chromatic filtering set (gate time of $0.3 \mu$ s plus BG-39 filter) was held constant throughout this investigation in addition to the spatial filtering on the Fourier plane (see schlieren stop in Figure 3).

On the other hand, the two tested routines produced different penetration results, as shown in Figure 5, where images labels "a" and " $b$ " are attached to reacting and non-reacting conditions:

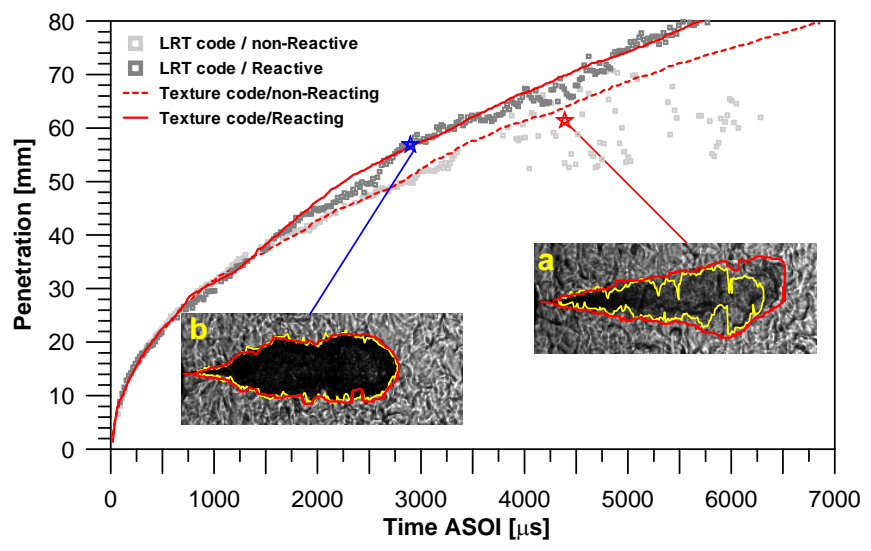

Figure 5. Time-resolved penetration values produced from LRT (gray) and texture (red) routines.. Image "a": HD nonreactive spray. Image " $b$ ”: $H D$ reactive spray.

Non-reactive sprays; Figure 5 shows the resulting temporal evolution of the spray penetration. It can be observed that both methodologies yield similar non-reactive penetration up to approximately $3500 \mu \mathrm{s}$ ASOI. After that, big differences in LRT results compared to that of the texture code can be observed. With longer spray penetration, higher fuel dilution in air at the spray tip is expected to cause a refractive index of 
the mixture similar to that of the background gases, leading to have a "ghost spray" that is no longer visible on those regions near the tip penetration, as was sketched in Figure $2 \boldsymbol{b}$ for inert sprays.

When the LRT routine is used for analysis of such diluted sprays, the tip penetration is either sub-predicted or wrongly estimated because of using a segmentation process based upon a threshold definition. The spray is distinguished from the background gases based on the digital levels counts along the image, instead of taking into account refractive index variations. When the texture code is used, the active zone criteria will always detect as an active pixel those regions where the fuel is present, because the continued interaction between the fuel-air mixture and the hot gases will always produce the shadowgraph effect. The red symbol in Figure 5, points out the penetration result extracted from the processed contour of the image labeled as "a". With the LRT code, detected contours are biased towards shorter penetration measurements; while the texture code produces a more accurate contour, which results in a tip penetration evolution closer to typical measurements $[13,17,19,20,26]$

Reactive-sprays: Removing soot luminosity made it possible to keep a more conventional digital level histogram for the reacting schlieren images. When using the LRT routine, the "white" soot did not influenced segmentation between the "black" spray and the "gray" hot-gases background. Furthermore, the enhanced schlieren effect within the flame (see Figure 4) also improved the processing performance of the texture code because the absence of the blooming phenomenon.

Some differences between LRT penetration (symbols in
Figure 5) and that from the texture code (solid line) can be observed on the temporal evolution of the reactive penetration. Authors think that such penetration differences are inherent to the different tip penetration criteria, instead of routines processing failure. As a summary, the following selection of the processing algorithm has been chosen:

- Authors have used the texture code results when nonreacting and reacting sprays penetrations are compared. The LRT code demonstrated limitations to provide non-reacting penetration results along a whole injection event.

- Reacting spray boundaries have been estimated by making use of the LRT code, which will be an input for the Lift-off length processing in the next section.

Some differences between LRT penetration (symbols in Figure 5) and that from the texture code (solid line) can be observed on the temporal evolution of the reactive penetration. Authors think that such penetration differences are inherent to the different tip penetration criteria, instead of routines processing failure. As a summary, the following selection of the processing algorithm has been chosen:

- Authors have used the texture code results when nonreacting and reacting sprays penetrations are compared. The LRT code demonstrated limitations to provide non-reacting penetration results along a whole injection event.

- Reacting spray boundaries have been estimated by making use of the LRT code, which will be an input for the Lift-off length processing in the next section.

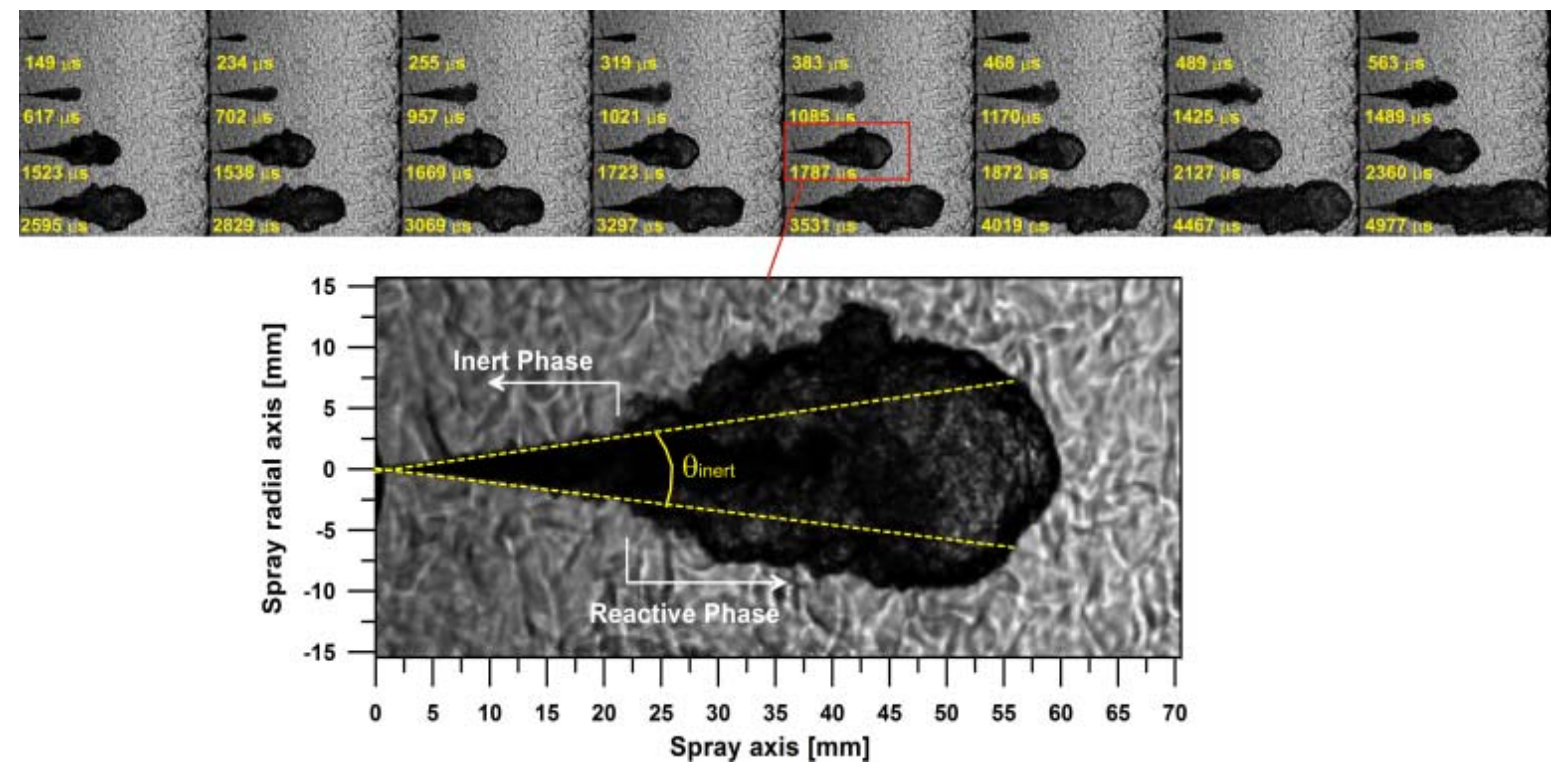

Figure 6. Top: Temporal evolution of a reacting case under $\mathrm{NO}$ conditions. $\mathrm{T}_{\text {air }}=826 \mathrm{~K}, \rho_{\text {air }}=21.2 \mathrm{Kg} / \mathrm{m}^{3}, \Delta P_{\text {inj }}=50 \mathrm{MPa}, \mathrm{nozzle}$ diameter $d_{0}=138 \mu \mathrm{m}$, and $n$-heptane as injected fuel. Bottom: zoom of the $1787 \mu \mathrm{s}$ ASOI image. 


\section{Schlieren Lift-off Length Measurements}

Figure 6 shows the time evolution of the spray morphology during an injection event. The spray can be described as a cone shape up to the auto-ignition event around $1170 \mu \mathrm{s}$ ASOI. Nevertheless, auto-ignition and subsequent diffusion flame development influences the spray morphology until the end of the injection. The bottom part of the Figure 6 clearly shows these differences between the reacting spray boundaries and the inert fixed contour. Therefore, reacting spray morphology has been divided into two different parts. First, an inert region from the nozzle hole to shortly upstream the liftoff zone, where only the liquid and vaporized-unburned fuel can be found. A second region has been considered downstream of the lift-off, in which heat release and combustion products exist. The transition from the inert phase to the reactive one has been defined as the location where the heat release induces a radial growth of the spray cross-section as a result of the decrease in local density $[17,18,30]$.

Based upon the evidences that the expansion phenomenon is (i) geometrically noticeable on the reacting spray structure and (ii) it can be first found at a location close to the $\mathrm{OH}^{*}$ chemiluminescence lift-off [20], authors have developed a routine to quantify this parameter from schlieren images, which can be later compared to the more conventional $\mathrm{OH}^{*}$ chemiluminescence measurement. This routine comprises the following steps as shown in Figure 7:
1.A reacting spray contour is detected from the LRT processing routine.

2. A cone shape contour is fitted to the initial inert part of the spray by means of a least-square algorithm (top of Figure 7). This initial part is defined by the $80 \%$ of a user-introduced initial estimation of the lift-off length.

3.At each location along the spray axis $(\mathrm{X})$, the crosssectional difference $\Delta \mathrm{R}$ between the detected reacting sprays and the inert fitted contour is computed $(\Delta \mathrm{R}=$ $\left.\mathrm{R}_{\text {react }}-\mathrm{R}_{\text {non-react }}\right)$.

4.Figure 7 shows the evolution of $\Delta \mathrm{R}$ along the spray axis in non-dimensional units, $(\Delta R / \Delta X$, where $\Delta X$ is the pixel length). Along the near-nozzle inert part of the spray $\Delta R / \Delta X$, is approximately zero. On the reacting part, $\Delta R / \Delta X$ first increases to a maximum and then, progressively decreases to zero. Schlieren lift-off length $\left(\mathrm{LoL}_{\mathrm{s}}\right)$ was defined as the distance from the nozzle to the location where this $\Delta \mathrm{R} / \Delta \mathrm{X}$ is $25 \%$ of the maximum value.

5.This process is repeated for both upper and lower contours and, $\overline{\boldsymbol{L o L}}_{S}$ in Figure 7 represents the average value.
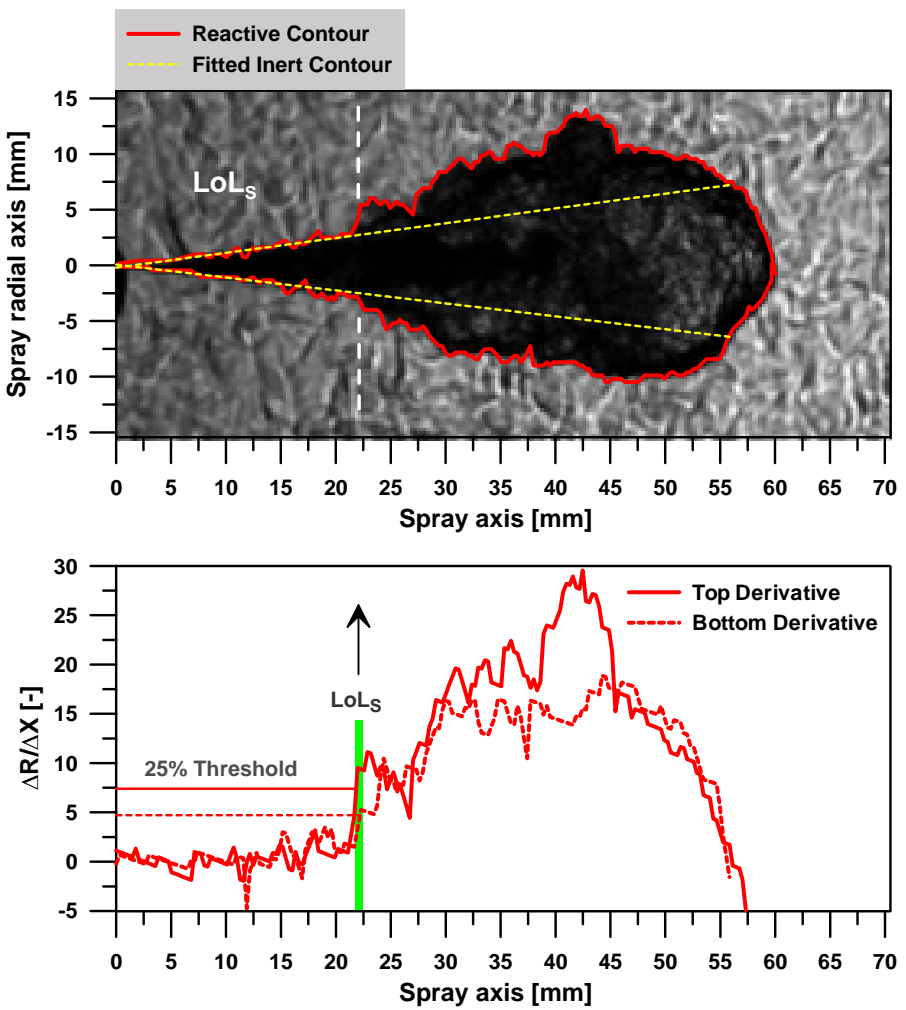

Figure 7. Top: Reactive (red solid line) and fitted inert contours (yellow dashed lines). Bottom: Cross-sectional differences for the two halves of the spray for the conditions specified in Figure 6. 


\section{OH Chemiluminescence and Image Processing}

The image processing procedure was similar to $[31,32,33,35,36]$, which has been adopted for ECN community for $\mathrm{OH}^{*}$ time-average images analysis of the "spray-A" conditions. As shown in Figure 8, $\mathrm{OH}^{*}$ chemiluminescence begins at a defined distance from the injector orifice with a sudden intensity increase followed by a leveling-off trend. The $\mathrm{OH}^{*}$ image is made up of two intense chemiluminescent lobes (top and bottom) which have been analyzed with the methodology described in [31,32]. According to that, lift-off length is defined as the average value of the locations where $\mathrm{OH}^{*}$ intensity level for each lobe exceeds $50 \%$ percent of the maximum intensity level for each half-image.
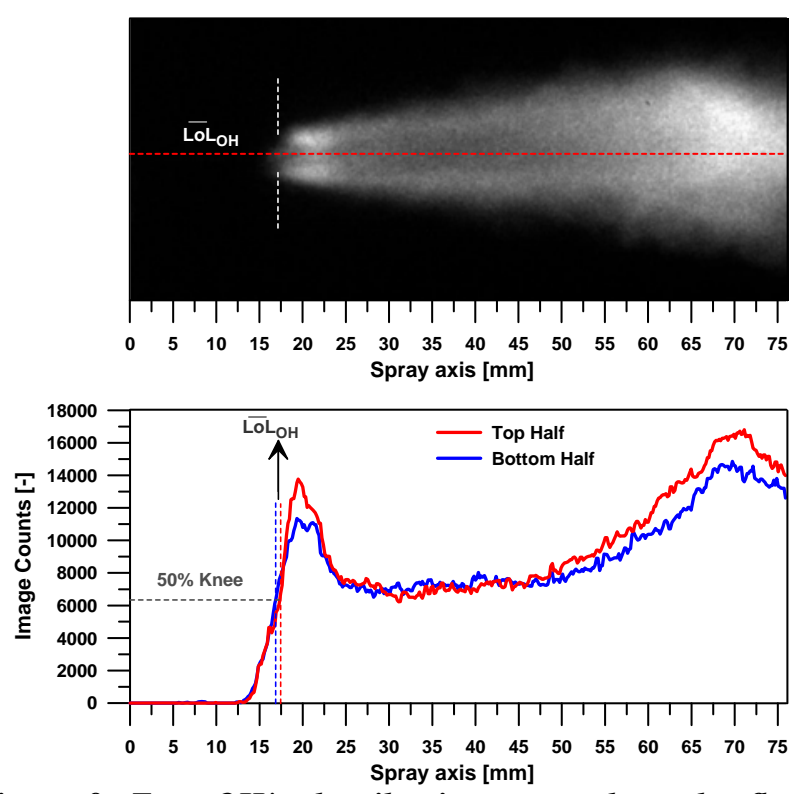

Figure 8. Top: $\mathrm{OH}^{*}$ chemiluminescence along the flame axis for the target spray-A conditions. Bottom: Lift-off length resulting from the image analysis through the "knee" methodology [30]. $T_{a i r}=900 \mathrm{~K}, \rho_{a i r}=22.8 \mathrm{Kg} / \mathrm{m}^{3}, \Delta P_{i n j}=150$ MPa and, nozzle diameter $d_{0}=90 \mu \mathrm{m}$.

\section{TEST MATRIX}

Two different sets of operating conditions have been used in this investigation:

The first study is aimed at evaluating the robustness of the schlieren lift-off processing routine using the boundary conditions of "spray-A" experiments. The study comprised the baseline condition together with a parametric variation of air temperature (at constant air density) and injection pressure in Table 2 , as proposed by the ECN. This community also established the boundary operating conditions of the test: injection settings (nozzles, fuel temperature, injection pressure, etc) and bulk-gas thermodynamics (temperature and density) in Table 2. Experiments were performed with SprayA fuel, which is n-dodecane, although some additional experiments were performed with n-heptane; for the same injection conditions but for different air temperature values (see Table 2).

The second study was meant to investigate the effect of heat release and injection pressure on the spray tip penetration by means of schlieren. Operating conditions comprise a baseline setting, denoted as "spray-NO", from which a test matrix that includes parametric variations of air density, air temperature and nozzle diameter has been performed. The whole study is part of a work that is currently in progress. For the purposes of this paper, a $138 \mu \mathrm{m}$ nozzle was used, and fuel was n-heptane. The injection pressure was varied in three values, and oxygen concentration was $21 \%$ for reacting conditions and $0 \%$ for inert ones.

\section{Table 2. Operating conditions}

\begin{tabular}{|c|c|c|}
\hline & Spray A conditions & Spray-NO \\
\hline \multicolumn{3}{|l|}{$\underline{\text { Injection Settings }}$} \\
\hline Fuel & n-dodecane; n-heptane & n-heptane \\
\hline Injector Type & Bosch Solenoid & Bosch Solenoid \\
\hline Nozzle Type & Mini-sac; Single Hole & $\begin{array}{c}\text { Mini-sac; Single } \\
\text { Hole }\end{array}$ \\
\hline Nozzle Diameter $[\mu \mathrm{m}]$ & 89 & 138 \\
\hline Nozzle Conicity & $\mathrm{K}=1.8$ & $\mathrm{~K}=2.9$ \\
\hline Energizing Time [ms] & 4 & 4 \\
\hline Injection Pressure [MPa] & 50,100 and 150 & 50,100 and 150 \\
\hline $\begin{array}{l}\text { Injector Coolant } \\
\text { Temperature }[\mathbf{K}]\end{array}$ & 363 & 363 \\
\hline \multicolumn{3}{|l|}{ Ambient Conditions } \\
\hline Bulk temperature $[\mathbf{K}]$ & $\begin{array}{c}\text { n-dodecane:750/800/850/900 } \\
\text { n-heptane: } 778 / 826 / 870\end{array}$ & 826 \\
\hline Bulk Density $\left[\mathbf{K g} / \mathbf{m}^{3}\right]$ & 22.8 & 21.2 \\
\hline Oxygen Concentration & $15 \%$ & $\begin{array}{c}21 \% \text { (reacting) } \\
0 \% \text { (non-reacting) }\end{array}$ \\
\hline
\end{tabular}

\section{RESULTS AND DISCUSSION}

\section{$\underline{\text { Relationship between } L o L_{S} \text { and } L O L} \underline{O H}$}

This section investigates on the relationship between the schlieren-derived Lift-off Length $\left(\mathrm{LoL}_{\mathrm{S}}\right)$ and the one obtained from $\mathrm{OH}^{*}$ chemiluminescence visualization $\left(\mathrm{LoL}_{\mathrm{OH}}\right)$. In that sense, it is worth recalling that the auto-ignition process in a diesel spray has a cool-flame period governed by both chemical kinetics and spray mixing dynamics. The cool-flame region has been identified and placed in that location where the flow expansion occurs in comparison to the inert spray flow [19]. After the cool-flame, a high-temperature auto 
ignited region is established at/or downstream the lift-off length where $\mathrm{OH}^{*}$ is present [33]. Because of the high $\mathrm{OH}^{*}$ emission, lift-off length measurements are feasible from the luminosity perspective, and $\mathrm{LoL}_{\mathrm{OH}}$ can be assumed to be linked to the high temperature zone of the flame. Experimental results [33] have shown that a cool flame can be found upstream of the quasi-steady lift-off length during the stabilized diffusion flame period. Such processes will probably induce local density changes, as well as radial expansion that may be captured by $\mathrm{LoL}_{\mathrm{S}}$.

Figure 9 shows representative instantaneous schlieren contours from the air temperatures and injection pressure sweeps overlaid onto $\mathrm{OH}^{*}$ images. When analyzing the effect of air temperature, it can be easily observed that at the highest temperature $(900 \mathrm{~K})$ lift-off results were essentially the same for both methodologies. When decreasing air temperature, measurements showed longer lift-off, with an increasing difference between both methods that is maximum for the lowest air temperature $(750 \mathrm{~K})$. Different reasons could justify these observations, e.g. too low sensitivity of the $\mathrm{OH}$ measurement system for the lowest temperatures, or also the definition of LoL based on $\mathrm{OH}^{*}$ intensity profile. Han and Mungal [37] also showed that streamlines in lifted flames can depart from those observed under inert conditions earlier than reaching the actual lift-off length. This effect could be substantial for longer lift-off conditions, and might also induced inhomogeneities within the flow, which could also contribute to plausible schlieren in this zone, although the extent of this effect is not clear. Finally, another reasonable explanation could be linked to the observed cool flame processes at the flame base. Observations in Figure 9 could indicate a cool-flame period that lasts longer (i.e. spatially larger) than the high temperature combustion for the lowest air temperature. This would suggest that $\mathrm{LoL}_{\mathrm{OH}}$ is somehow biased towards the high temperature auto-ignition, while $\mathrm{LoL}_{\mathrm{S}}$ is more biased towards the low temperature combustion phase.

Figure 9 also shows that chemiluminescence was enhanced towards the nozzle exit when decreasing injection pressure, from $150 \mathrm{MPa}$ (bottom-right) to $100 \mathrm{MPa}$ (middle-right) and to $50 \mathrm{MPa}$ (top-right). The same trend was obtained for both $\mathrm{LoL}_{\mathrm{OH}}$ and $\mathrm{LoL}_{\mathrm{S}}$, and in this case the sensitivity of both measurement methods to the parametric variation is similar, compared to the air temperature variation. Because of the constant temperature $(750 \mathrm{~K})$, pure chemical processes should remain essentially unchanged. Even the mixture fraction field should not be dependent on injection pressure [34]. However the change in injection pressure acts upon the scalar dissipation rate as well as on the residence times. Altogether, and according to the previous results in the temperature parametric variation, changing the injection pressure seems to modify both low and high-temperature stabilization locations in the same direction and almost with the same proportionality.

While in Figure 9 only the extreme conditions for air temperature and injection pressure sweeps have been shown,
Figure 10 presents the whole set of lift-off results for both methodologies. The solid line figure represents the bisector upon which both lift-off measurements would fall if both techniques were identical. Each symbol type corresponds to eight samples for each air temperature considered on the spray-A parametric study in Table 2.

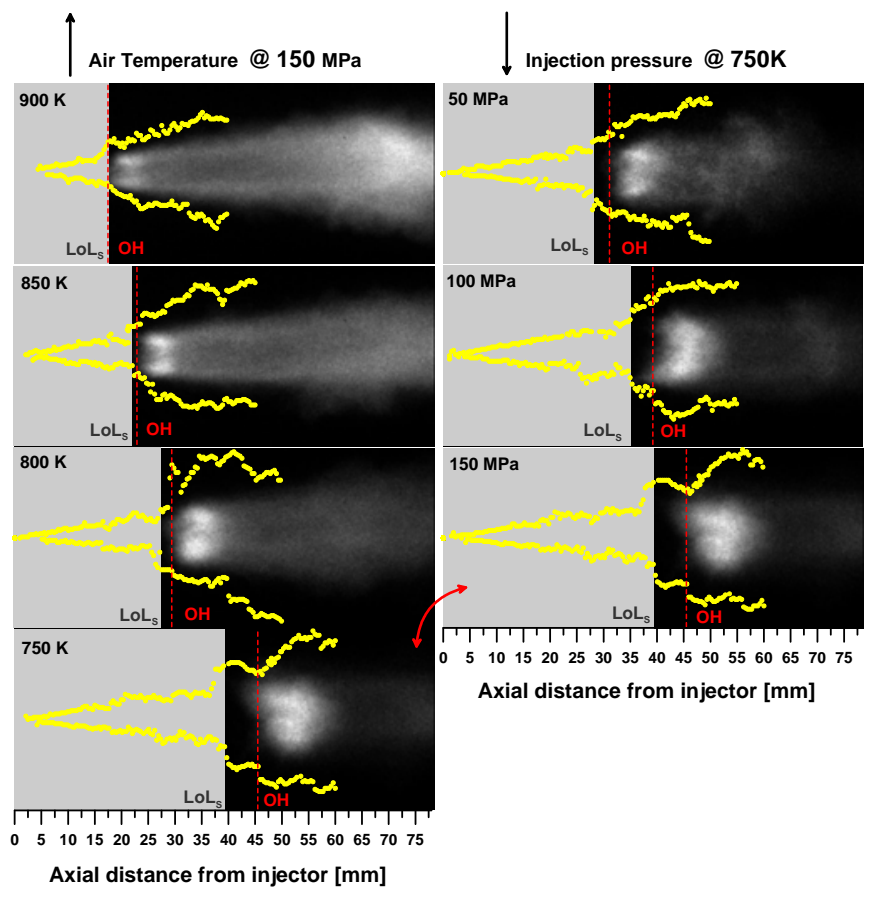

Figure 9. OH images and instantaneous schlieren contours (yellow dots) of the reacting sprays tested under spray-A conditions in Table 2. Gray areas masked regions upstream

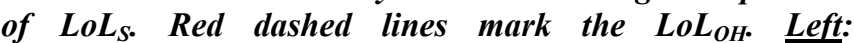
Temperature effect; instantaneous contours correspond to $2300 \mu \mathrm{s}$ ASOI. Right: Injection pressure effect; instantaneous contours correspond to $3300 \mu \mathrm{s}$ ASOI.

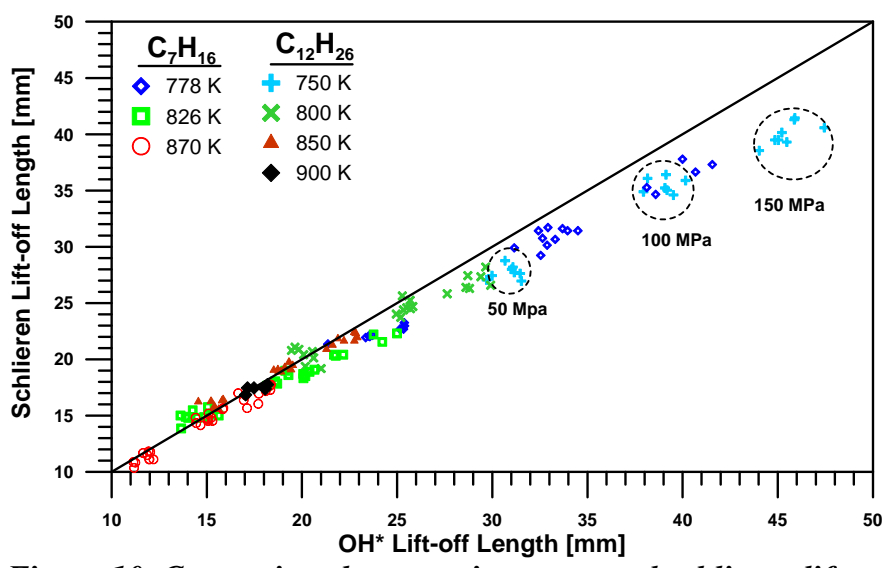

Figure 10. Comparison between time-averaged schlieren liftoff $\overline{\mathrm{LoL}_{S}}$ and $\mathrm{LoL}_{\mathrm{OH}}$ for the full matrix in Table 2. Each

symbol type corresponds to a temperature value, which includes a sweep of injection pressure.

Page 10 of 18 
LoL $_{S}$ values have been calculated by time averaging instantaneous values during the same gating period set on the $\mathrm{OH}$ camera (from 2 ASOI to 5 ASOI, except for the lowest temperature, where long ignition delay was above $2 \mathrm{~ms}$ and hence $\mathrm{OH}^{*}$ recording was performed from 3 to $5 \mathrm{~ms}$ to avoid imaging ignition timings).

\section{Two different trends can be observed:}

- First, the comparison brings out a relatively linear behavior up to $25 \mathrm{~mm}$, where both methodologies produce essentially the same LoL value.

- Secondly, as the lift-off increases over $25 \mathrm{~mm}$, a nonlinear trend is observed, LoL $\mathrm{L}_{\mathrm{S}}$ produces shorter lift-off lengths than $\mathrm{LoL}_{\mathrm{OH}}$ analysis. Divergences are maximum at the lowest air temperatures $(750 \mathrm{~K})$ and highest injection pressure (150 MPa).

Even though most of the measurements show $\mathrm{LoL}_{\mathrm{S}}<\mathrm{LoL}_{\mathrm{OH}}$, singular points in Figure $\mathbf{1 0}$ below $25 \mathrm{~mm}$ showed a subtle reversed trend. Authors believe that the larger $\mathrm{LoL}_{S}$ measurements are due to random turbulence of the reacting spray structure, rather than the $\mathrm{OH}^{*}$ existence upstream the expansion region; nevertheless, such differences (approximately 1-2 $\mathrm{mm}$ ) can be considered statistically supported by several lift-off length variability observations $[27,28]$.

Another way to determine the accuracy of the schlieren lift-off methodology is the common practice of correlating such parametric studies to different engine parameters to quantify sensitivities. Equation 2 shows the mathematical function that has been used to quantify LoL as a function of: the injection velocity $\left(\mathrm{U}_{0}\right)$ and, air temperature $\left(\mathrm{T}_{\text {air }}\right)$. Table 3 summarizes the coefficients found by applying Equation 2 to the experimental results found in this investigation. Such analysis has been applied to both $\mathrm{LoL}_{\mathrm{OH}}$ and $\mathrm{LoL}_{\mathrm{S}}$ to evaluate their consistency and to explore relative sensitivities to operating parameters.

$$
\operatorname{LoL}[\mathrm{mm}]=\boldsymbol{k} \cdot \boldsymbol{U}_{0}^{a}[\mathrm{~m} / \mathrm{s}] \cdot \boldsymbol{T}_{\text {air }}^{b}[\mathrm{~K}]
$$

Table 3. Regression coefficients obtained for the Lift- Off Length scaling function shown in Equation 2. Pickett et al. [33] and Payri et al. [36] coefficients are also reported for reference.

\begin{tabular}{|cccccc|}
\hline $\begin{array}{c}\text { Parameters } \\
\text { Exponents }\end{array}$ & $\boldsymbol{k}$ & $\mathbf{U}_{\mathbf{0}}$ & $\mathbf{T}_{\text {air }}$ & $\mathbf{\% R}^{2}$ & $\mathbf{R M S E}$ \\
\hline Pickett etal. [33] & - & $\mathbf{a}$ & $\mathbf{b}$ & - & - \\
\hline Payri et al. [36] & - & 1 & -3.74 & - & - \\
\hline OH- $\mathrm{C}_{12} \mathrm{H}_{26}$ & $1.81 \mathrm{E}+15$ & 0.71 & -5.42 & 98.39 & 1.10 \\
OH- $\mathrm{C}_{7} \mathrm{H}_{16}$ & $9.65 \mathrm{E}+13$ & 0.75 & -5.04 & $\frac{93.38}{-}$ & 0.78 \\
\hline Schlieren- $\mathrm{C}_{12} \mathrm{H}_{26}$ & $1.30 \mathrm{E}+13$ & 0.61 & -4.60 & 98.58 & 0.80 \\
Schlieren- $\mathrm{C}_{7} \mathrm{H}_{16}$ & $7.15 \mathrm{E}+13$ & 0.64 & -4.91 & 95.07 & 0.58 \\
\hline
\end{tabular}

The statistical analysis of $\mathrm{LoL}_{\mathrm{OH}}$ and $\mathrm{LoL}_{\mathrm{S}}$ measurements (see Table 3) was performed for each fuel separately. $k$ values for cited works were not included because the corresponding parametric studies considered variables different from the present one. For example, if one study included density or nozzle diameter, $k$ value differences could be quite large. In general, the coefficients obtained from the least-square regression show a high reliability of the model regardless the methodology, as denoted by $\mathrm{R}^{2}>\% 97$. It is also noticeable that temperature and injection pressure sensitivities observed in Figure 9 only for the extreme conditions are somehow confirmed for the whole set of data: $\mathrm{LoL}_{\mathrm{OH}}$ and $\mathrm{LoL}_{\mathrm{S}}$ show very similar coefficients for the injection velocity, while the temperature exponent for the $\mathrm{OH}$ measurement is higher, which indicates a higher sensitivity of lift-off towards this parameter.

When coefficients (e.g. n-dodecane data) are compared to the ones reported by Payri et al. [36] in Table 3 (with the same experimental environment and the closest methodology), consistency to the modeled coefficients has been observed. In terms of the injection velocity, the modeled trends varied from $\mathrm{U}_{\mathrm{o}}{ }^{0.71}$ and $\mathrm{U}_{\mathrm{o}}{ }^{0.75}$ depending on the fuel, compared to $\mathrm{U}_{\mathrm{o}}^{0.88}$ in [36], while air temperature trends varied from $\mathrm{T}_{\text {air }}{ }^{-5.42}$ and $\mathrm{T}_{\text {air }}{ }^{-5.04}$ depending on the fuel, compared to $\mathrm{T}_{\text {air }}{ }^{-5.26}$ in [36]. However, neither the injection velocity $\mathrm{U}_{0}{ }^{1}$ nor the air temperature $\mathrm{T}_{\text {air }}{ }^{-3.5}$ trends reported by Pickett et al. [33] are obtained in these experiments. One cannot overlook the fact that the empirical nature of such trends could be the cause for the differences observed. Fuel properties, injection pressure levels, nozzle diameters and maybe other factors that changed between experimental environments and procedures could contribute to the differences among models.

Before moving forward to new results, one cannot overlook on the fact that lift-off analysis is commonly based on the quasisteady state of the flame, nevertheless, the turbulent nature of the injection as well the injector performance could hide issues that could support dispersions on the data shown in Table 3. Pickett et al. in [33] observed that the assumed quasi-steady state of the flame is somehow contradictory with the fact that the injection history may change the lift-off length during the injection, moving the final lift-off length location upstream from the first auto-ignited region. In fact, when the ignition is induced by plasma generation on the upstream region [38], tests showed a very long time period $(>10 \mathrm{~ms})$ to reach the same lift-off observed in a natural ignition test. Furthermore, there are some indications that nozzles used by the ECN community (like the one used in this experiments [28]) have a needle that oscillates [39]. Such oscillations can induce changes on the fuel-air mixing as on the location of the autoignition region. Therefore, these observations can be a reasonable explanation to the non-linearity trends found on the injection velocity coefficients in Table $\mathbf{3}$, as well as on the temporal variability of the $\mathrm{LoL}_{\mathrm{S}}$. In addition, the used of timeresolved measurements as the performed in this study could help understanding how the transient injection affects the liftoff length. 


\section{Time-resolved LoL $L_{S}$ and Reactive Spray Penetration}

The top part of Figure 11 presents the temporal evolution of the spray tip penetration and the instantaneous $\mathrm{LoL}_{\mathrm{S}}$ for the baseline spray-NO condition in Table 2. The ensemble average of 10 cycles is presented, together with a shaded area corresponding to one standard deviation for both the reacting and non-reacting penetrations. The effect of the combustion process is evaluated in terms of the differences in penetration between the reacting spray and the non-reacting one $\left(\mathrm{S}_{\text {React }}-\right.$ $\left.\mathrm{S}_{\text {non-React }}\right)$ at the bottom of Figure 11. In this case, the shaded area encloses the standard deviation of penetration differences.
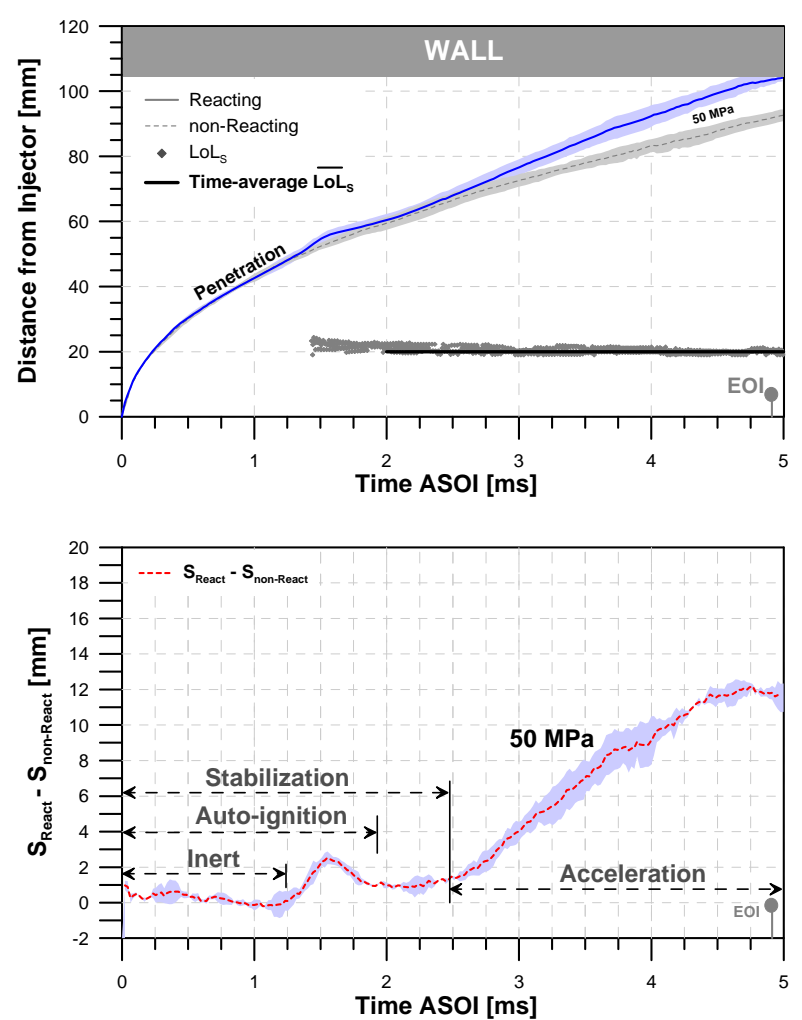

Figure 11. Spray penetration and LoL for the NO conditions in Table 2. Injection pressure was $\triangle P_{i n j}=50 \mathrm{MPa}$.

The reacting tip has been found to undergo different stages as injection progresses. As expected, along the period prior to the auto-ignition process, the reacting case does not experiment any difference in penetration when compared to the nonreacting one. According to schlieren images, auto-ignition process occurs at approximately $1170 \mu \mathrm{s}$ ASOI (radial growth of the spray in Figure 6). From these instant up to $1750 \mu \mathrm{s}$ ASOI, the reacting spray undergoes a sudden increase in the spray penetration, when compared to the non-reacting one. Maximum difference in penetration during this phase is around $2.5 \mathrm{~mm}$. After this initial peak in penetration rate, the reacting spray seems to decelerate if compared to the inert one, as observed by the fact that spray tip penetration tends to match that of the non-reacting spray from $1750 \mu$ s ASOI to

Page 12 of 18
$2500 \mu \mathrm{s}$. Eventually, the reacting spray penetration enters an acceleration period, with an increasing difference above the non-reacting inert one.

The gray symbols in Figure 11 (bottom) describe the temporal

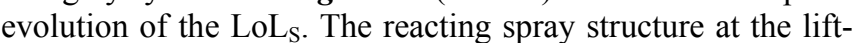
off length is virtually steady because there is no change on the boundary conditions along the injection event (e.g. air velocities on optical engines and rapid compression machines). However, dispersion can be observed during the temporal description which can be attributed to contour oscillations because of the turbulent nature of the spray (see Figure 7) or detected flame contour (inherent to processing routines) or needle oscillations, as discussed on the previous section. Such variability has also been observed in $\mathrm{OH}$ luminosity in $[35,36]$. Despite such variability, which might be indeed expected for these turbulent sprays, the quasi-steady average $\overline{\mathbf{L o L}_{S}}$ in the bottom of Figure 11 can be used s as a characteristic value.

The previous ignition sequence shows that, during the early combustion stages, inert and reacting penetrations are quite similar. Penetration differences between reacting and inert cases are longer than $5 \mathrm{~mm}$ only around $1.25 \mathrm{~ms}$ after autoignition, which is a relatively long time in terms of engine operation. As a consequence, if injection duration is not long enough, or optical windows are not large enough, the full phenomenon may not be observed, and this could explain why reacting spray penetration does not depart from the nonreacting one for some of the results in the literature [18].

The evolution of reacting spray tip penetration also agrees with observations by Siebers [17], who makes a distinction between inert non-vaporizing, inert vaporizing and reacting sprays. In terms of spray tip penetration the following conclusions are drawn:

- For vaporizing sprays, an overall increased density is the consequence of the cooling process induced by vaporization, what is traduced into a slower penetration than non-vaporizing sprays.

- Besides the vaporization effect, after the combustion process, the reacting spray decelerates less rapidly than non-vaporizing sprays leading to a faster reacting penetration.

The present investigation can only evidence differences between reacting and non-reacting vaporizing sprays, but conclusions are coherent with the previous trends.

On the other hand, Desantes et al. [30] made use of a 1D spray model to investigate on a possible sequence of events during the spray auto-ignition and early combustion. They observed that auto-ignition creates an unbalance within the spray flow as a result of combustion-induced drop in density, which can only be recovered by a transient acceleration phase that ends up when momentum flux along the spray drops to their initial 
values. Even though their model might have included a singlestep infinitely fast chemistry to describe transition from inert to full reacting conditions, it is clear that the acceleration period existed. Compared to those modeling results, initial stages observed in the experiments (auto-ignition and stabilization) can be probably due to the time-finite transition between inert and reacting conditions.

To sum up, the temporal evolution of a reactive spray can be described as indicated in top of the Figure 11:

1. Non-reacting phase until auto-ignition occurs, where penetration falls upon the non-reacting inert case.

2. Auto-ignition phase where the spray penetration suddenly increases because of the inert-reacting transition, which entails a drop in local density and a corresponding spray volume expansion.

3. Stabilization phase, where the reacting tip penetration tends to decrease progressively and shortly stabilize compared to the non-reacting one. It may be hypothesized that the initial inert flow is somehow 'destroyed' by the transition to reacting conditions, and some time is needed for local flow conditions to rearrange to those of a reacting spray.

4.Acceleration phase, where the tip penetration eventually detaches from the trends of a non-reacting spray by progressing faster.

\section{Injection Pressure Effect on Reacting Spray Penetration}

Figure 12 shows the temporal evolution of the reacting spray tip and LoLs measurements under the NO conditions for a parametric variation of injection pressure. Information is presented either until the arrival of the flame to the optical window limits or until the End of Injection (EOI). Similar to what has been presented before, the different phases of the spray tip penetration (inert \& auto-ignition \& stabilization \& acceleration) can be observed for all three injection pressure levels. Differences among all three cases are related to the timings of the different phases as well as to the degree of the observed differences between reacting and inert behavior. In this sense, increasing injection pressure advances subsequent penetration-related phases. There is an obvious limitation in the optical window limit, which prevents from gathering experimental evidences for late injection times. For example, it may seem that for $150 \mathrm{MPa}$ tests, the auto-ignition penetration does not increase as much as to produce substantial differences compared to the non-reactive penetration. However, one can still state that in general terms the three phases mentioned above for the spray tip penetration are still maintained.

Page 13 of 18

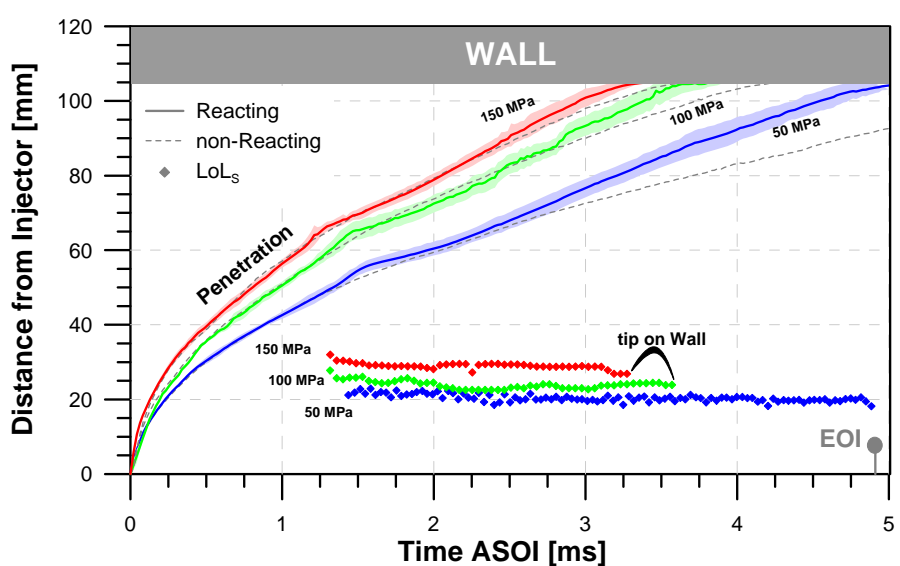

Figure 12. Injection Pressure influence over the reacting penetration at NO operating conditions shown in Table 2.

Because the scope of this investigation is the analysis of reacting vs. non-reacting spray evolution, it is interesting to use some kind of normalization that enables the comparison of tests under different boundary conditions. Otherwise, as shown in Figure 12, the analysis has to be based on a comparison for single cases, which makes it more complicated.

Due to the similarities between Diesel sprays and turbulent gas jets, length and time scaling factors has been used. Such factors are meant to normalize the penetration and temporal evolution according to Equations 3 and 4 . Where, $S$ is the vapor penetration at any time instant $t, \mathrm{U}_{\mathrm{o}}$ is the nozzle exit velocity; $\rho_{\mathrm{f}}$ and $\rho_{a}$ are the fuel and gas densities, respectively. Both spray type penetration and time are divided by the equivalent diameter $d_{e q}$, which is a scale of the gas jet flow commonly used in mixing controlled models [14].

$$
\begin{aligned}
& S^{*}=\frac{S}{d_{0} \cdot \sqrt{\frac{\rho_{f}}{\rho_{a}}}}=\frac{S}{d_{e q}} \\
& t^{*}=t \cdot \frac{U_{0}}{d_{0} \cdot \sqrt{\frac{\rho_{f}}{\rho_{a}}}}=\frac{t \cdot U_{0}}{d_{e q}}
\end{aligned}
$$

Such scaling laws are similar to those introduced by Nabers and Siebers in [13]. They accounted for spray penetration dispersion in terms of cone angle variations by adding the form $\tan (\theta / 2)^{-1}$ in Equations 3 and 4 . In this case, spray cone angle has not been used, due to inherent difficulties in deriving this parameter accurately from schlieren images as discussed in [34]. Furthermore, this parameter should be mainly dependent on ambient density conditions, which are constant throughout this work.

Figure 13 shows the dimensionless scaled penetrations, where scattering areas have been suppressed in order to easily visualize the average penetrations (solid lines). The EOI labels 
on the time axis indicate the corresponding End of Injection in normalized values, according to Equation 4. Prior to autoignition all normalized penetration values collapsed upon a single inert curve, mainly due to the velocity scaling factor on the time axis. At auto-ignition, spray penetration was observed to follow the description in Figure 11, Note that ignition delay trends, marked with arrows in Figure 13 show that an increase on the injection pressure results in an increase of the autoignition delay in normalized scales, which is the contrary to observations made in absolute scales in Figure $\mathbf{1 2}$ as well as in literature [27,40,41]. This apparent incoherency results from the fact that time a normalization in performed terms of mixing times, while start of combustion is mainly governed by chemical times, which should not be too dependent on the injection pressure.

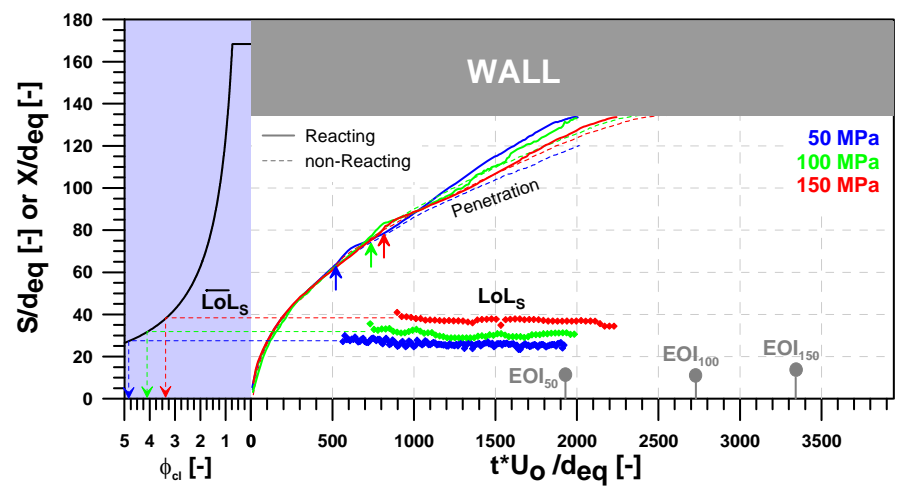

Figure 13. Non-dimensional spray penetration and LoL of NO conditions previously shown in Figure 12. Symbols show the time-resolved $\mathrm{LoL}_{s}$, and $\phi_{c l}$ is the equivalence ratio along the spray centerline computed as described in [14].

During the stabilization phase, the penetration has been observed to go close or even below the non-reacting penetration. As for the acceleration phase, reacting penetration seems to depart more pronouncedly from the inert one the lower the injection pressure. This indicates a stronger effect of heat release on spray mixing process compared to the inert case for lower injection pressures.

In addition to penetration results, centerline equivalence ratio distribution is presented on the left-hand side plot in Figure 13. This parameter is obtained via a $1 \mathrm{D}$ model calculation based on the gas/jet theory of conservation of mass, momentum and energy assuming a mixing-limited spray and Gaussian radial profiles for fuel conservative properties. A more detailed model description and calibration can be found in $[14,30]$ and $[25,26]$, respectively. In the present study, the model was used to estimate the equivalence ratio of the fuelair mixture at the $\mathrm{LoL}_{\mathrm{S}}$, which should be an indicator of the maximum equivalence ratio found within the reacting spray region, from the flame base till the tip. In that sense, the 1D calculation was performed using the real injection rate as measured by the Bosch method [42] while, the cone angle $(\theta)$ was used to make the modeled spray penetration fits the experimental one, in agreement with the methodology presented in [43].

Page 14 of 18
In agreement with turbulent gas jet theory, comparison of different injection pressures showed no influence on equivalence ratio distribution in the figure, due to the fact that the increasing mass flow at the nozzle is compensated by an increased air entrainment $[30,44]$. Therefore, a single spray centerline evolution of the fuel-air equivalence ratio shows a $\phi_{\mathrm{LOLS}}$ trend that is inversely proportional to the LoL values. i.e. $\phi_{50} \approx 4.8>\phi_{100} \approx 4.1>\phi_{150} \approx 3.7$. As the maximum $\phi$ value drops, the whole mixture distribution within the flame goes leaner when increasing injection pressure. The previous quantification indicates an inverse relationship between mixture equivalence ratio and combustion-induced modification of the mixing process. In other words, a richer fuel-air mixture is expected to produce a more substantial modification of the mixing process when going to reacting conditions.

\section{SUMMARY/CONCLUSIONS}

The initial objective of this study was to investigate on the reacting penetration of direct injection Diesel sprays by means of high-speed schlieren visualization. Non-reacting and reacting sprays were compared in a High-Pressure\&HighTemperature combustion vessel. Using a wide-range set of operating conditions that included a parametric variation of the ECN spray-A, flame lift-off length was also investigated by means of both schlieren imaging and $\mathrm{OH}^{*}$ Chemiluminescence. The main conclusions that can be drawn from the reported work are:

1. The applicability of the schlieren visualization on reacting sprays studies has been demonstrated to provide an accurate description of the transient evolution of Diesel flames. Despite the presence of soot radiation, an adequate schlieren setup enabled the definition of the main spray macroscopic parameters, i.e. tip penetration and radial growth. Timeresolved Lift-off Length was also measured from schlieren images, and even auto-ignition delay can be observed from such image sequences. The number of parameters that have been measured confirms that high-speed schlieren imaging can be considered as a valuable diagnostic technique for reacting spray studies.

2. An optical set-up has been employed to limit the soot radiation effect upon schlieren images. For that purpose, spatial (adequate cut-off at the Fourier plane), temporal (short exposure) and chromatic filtering have been applied, which resulted in a high-contrast schlieren spray image unaffected by blooming issues, which could be easily processed to derive the macroscopic parameters during both the inert and reacting phases.

3. Apart from calculating spray tip penetration, the resulting schlieren images provided a time-resolved measurement of the lift-off length. This measurement was based upon a purposedeveloped routine that detected the closest location to the nozzle where radial expansion of the reacting spray compared 
to the inert one occurred. Experiments have been performed to compare this technique to the more standard $\mathrm{OH}^{*}$ chemiluminescence measurements. Results showed that for LoL lower than about $25 \mathrm{~mm}$, both techniques produced essentially the same result, while for longer values the schlieren-derived parameter was shorter. This can indicate that $\mathrm{LoL}_{\mathrm{S}}$ is a likely indicator of the cool-fame chemistry at the flame base, compared to $\mathrm{OH}^{*}$ which mainly occurs at hightemperature locations.

4. The reacting spray tip penetration behavior was analyzed based upon the comparison with the non-reacting case. Tests showed three singular phases after start of combustion:

- Auto-ignition, where a relatively fast expansion of the inert spray occurs, both in radial and axial directions. This phase results in an increased penetration peak compared to the inert spray case.

- Stabilization, where the difference between the reacting and inert spray tip remains approximately constant, with a slightly higher reacting spray penetration.

- Acceleration, where the reacting spray eventually penetrates faster than the inert one.

5. The previously defined reacting penetration phases were also observed when the injection pressure was varied, although the timings and intensity of the different phases were modified. A decrease in injection pressure resulted in richer combustion mixtures that produce a more significant departure of the spray mixing process when comparing inert and reacting conditions.

6. The observed time and temporal scales indicate that the observation of the phenomenon depends on several factors:

- The optical set-up influences the schlieren phenomenon sensitivity, i.e. the penetration measurements.

- Limited optical access size could prevent from observing the acceleration phase for some operating conditions (e.g. low air density, high injection pressure).

- Short injection durations could also disable the eventual observation of the acceleration phase, which occurs relatively late in terms of real engine injection times.

To sum up, the reacting spray behavior has been characterized, but further work is needed to clarify the observed phenomena.

\section{REFERENCES}

1. Dec, J., "A Conceptual Model of DI Diesel Combustion Based on Laser-Sheet Imaging," SAE Technical Paper 970873, 1997, doi: 10.4271/970873.

2. Musculus M. P. B, Miles P. C., and Pickett L. M., "Conceptual Models for Partially Premixed LowTemperature Diesel Combustion," Progress in Energy

Page 15 of 18 and Combustion Science 39(2-3): 246-283, 2013, doi: 10.1016/j.pecs.2012.09.001.

3. Benajes J., García-Oliver, J. M., Novella R., and Kolodziej C., "Increased Particle Emissions from Early Fuel Injection Timing Diesel Low Temperature Combustion," Fuel 94: 184-190, 2012, doi: 10.1016/j.fuel.2011.09.014.

4. Upatnieks, A. and Mueller, C., "Clean, Controlled DI Diesel Combustion Using Dilute, Cool Charge Gas and a Short-Ignition-Delay, Oxygenated Fuel," SAE Technical Paper 2005-01-0363, 2005, doi: 10.4271/2005-01-0363.

5. Koban, W. and Schulz, C., "Toluene Laser-Induced Fluorescence (LIF) Under Engine-Related Pressures, Temperatures and Oxygen Mole Fractions," SAE Technical Paper 2005-01-2091, 2005, doi: 10.4271/200501-2091.

6. Le Coz, J. and Hermant, L., "Quantification of Fuel Concentrations and Estimation of Liquid/Vapor Ratios in Direct Injection Gasoline Sprays by Laser-Induced Fluorescence," SAE Technical Paper 2001-01-0916, 2001, doi: 10.4271/2001-01-0916.

7. Schulz C., and Sick V., "Tracer-LIF diagnostics: quantitative measurement of fuel concentration, temperature and fuel/air ratio in practical combustion systems," Progress in Energy and Combustion Science 31(1): 75-121, 2005, doi: 0.1016/j.pecs.2004.08.002.

8. Suzuki, M., Nishida, K., and Hiroyasu, H., "Simultaneous Concentration Measurement of Vapor and Liquid in an Evaporating Diesel Spray," SAE Technical Paper 930863, 1993, doi: $10.4271 / 930863$.

9. Gao J., and·Nishida K., "Laser Absorption-Scattering Technique Applied to Asymmetric Evaporating Fuel Sprays for Simultaneous Measurement of Vapor/Liquid Mass Distributions," Applied Physics B 101: 433-443, 2010, doi: $10.1007 / \mathrm{s} 00340-010-4059-\mathrm{x}$.

10. Klein-Douwel R. J. H., Frijters P. J. M., Somers L. M. T., de Boer W. A. et al., "Macroscopic Diesel Fuel Spray Shadowgraphy Using High Speed Digital Imaging in a High Pressure Cell," Fuel 86(12-13): 1994-2007, 2007, doi: $10.1016 /$ j.fuel.2006.11.039.

11. Lillo P., Pickett L., Persson H., O. Andersson et al.," Diesel Spray Ignition Detection and Spatial/Temporal Correction, ” SAE Int. J. Engines 5 (3): 1330-1346, 2012, doi: $\underline{10.4271 / 2012-01-1239}$.

12. Pickett L., Genzale C., Bruneaux G., Malbec L. et al., "Comparison of Diesel Spray Combustion in Different High-Temperature, High-Pressure Facilities", SAE Int. J. Engines 3 (2):156-181, 2010, doi: 10.4271/2010-01-2106. 
13. Naber, J. and Siebers, D., "Effects of Gas Density and Vaporization on Penetration and Dispersion of Diesel Sprays," SAE Technical Paper 960034, 1996, doi: $10.4271 / 960034$.

14. Pastor, J., López J., Pastor J. M. and García-Oliver J. M, "A 1D Model for the Description of Mixing-Controlled Inert Diesel Sprays," Fuel 87: 2871-2885, 2008, doi: $\underline{10.1016 / \text { j.fuel.2008.04.017. }}$

15. M.P.B. Musculus, K. Kattke, Entrainment Waves in Diesel Jets, SAE Int. J. Engines 2 (1): 1170-1193, 2009, doi: $10.4271 / 2009-01-1355$.

16. J.J. López, R. Novella, A. García and J.F. Winklinger, Mathematical and Computer Modelling 57 (7-8) 18971906 (2013), doi: 10.1016/j.mcm.2011.12.030.

17. Siebers D, "Chapter 6 in Flow and Combustion in Reciprocating Engines", Springer-Verlag Berlin Heidelberg: 257-308, 2009, doi: 10.1007/978-3-54068901-0 1.

18. H. Kobayashi, T. Kamimoto and S. Matsuoka, "A Photographic and Thermodynamic Study of Diesel Combustion in a Rapid Compression Machine," SAE Technical Paper, 810259, 1982.

19. Pickett, L. and Hoogterp, L., "Fundamental Spray and Combustion Measurements of JP-8 at Diesel Conditions," SAE Int. J. Commer. Veh. 1(1):108-118, 2009, doi: $\underline{10.4271 / 2008-01-1083}$.

20. Pickett, L., Kook, S., and Williams, T., "Visualization of Diesel Spray Penetration, Cool-Flame, Ignition, HighTemperature Combustion, and Soot Formation Using High-Speed Imaging," SAE Int. J. Engines 2(1):439-459, 2009, doi: 10.4271/2009-01-0658.

21. Marciniak, B. and Wysocki M., "Discrimination Between Electronic and Optical Blooming in an InSb Focal-Plane Array Under High-Intensity Excitation," Infrared Physics \& Technology 51(3): 137-145, 2008. doi: 10.1016/j.infrared.2007.08.002.

22. Pastor J.V, Arrègle J., García and Zapata D. L., Segmentation of Diesel Spray Images with LogLikelihood Ratio Test Algorithm for non-Gaussian Distributions," Applied Optics 46 (6): 888-899, 2007, doi: $\underline{10.1364 / \mathrm{AO} .46 .000888}$.

23. Settles, G.S., Schlieren and Shadowgraph Techniques: Visualizing Phenomena in Transparent Media, SpringerVerlag Berlin Heidelberg, pp: 25-38, 2001, ISBN 978-3540-66155-9.

Page 16 of 18
24. Bermúdez, V., García, J., Juliá, E., and Martínez, S., "Engine with Optically Accessible Cylinder Head: A Research Tool for Injection and Combustion Processes," SAE Technical Paper 2003-01-1110, 2003, doi: 10.4271/2003-01-1110.

25. Pastor, J., Payri, R., Garcia-Oliver, J. and Nerva, J., "Schlieren Measurements of the ECN-Spray A Penetration under Inert and Reacting Conditions," SAE Technical Paper 2012-01-0456, 2012, doi: 10.4271/2012$\underline{01-0456 .}$

26. Pastor, J., Payri, R., Garcia-Oliver, J., and Francisco J. Briceño, "Analysis of Transient Liquid and Vapor Phase Penetration for Diesel Sprays Under Variable Injection Conditions," Atomization and Sprays (6): 503-520, 2011, doi: 10.1615/AtomizSpr.2011003721.

27. Engine Combustion Network (ECN), http://www.sandia.gov/ecn/cvdata/targetCondition/sprayA .php.

28. Engine Combustion Network (ECN), http://www.cmt.upv.es/ECN.aspx.

29. http://www.newport.com/Colored-GlassFilters/141135/1033/info.aspx\#tab_Specifications

30. Desantes J.M, Pastor J.V., García-Oliver J.M. and Pastor J.M., "A 1D Model for the Description of MixingControlled Reacting Diesel Sprays," Combustion and Flame 156: 234-249, 2009, doi: $\underline{0.1016 / \text { j.combustflame.2008.10.008. }}$.

31. Higgins, $B$. and Siebers, D., "Measurement of the Flame Lift-Off Location on DI Diesel Sprays Using OH Chemiluminescence," SAE Technical Paper 2001-010918, 2001, doi: 10.4271/2001-01-0918.

32. Siebers, D. and Higgins, B., "Flame Lift-Off on DirectInjection Diesel Sprays Under Quiescent Conditions," SAE Technical Paper 2001-01-0530, 2001, doi: 10.4271/2001-01-0530.

33. Pickett, L., Siebers, D., and Idicheria, C., "Relationship Between Ignition Processes and the Lift-Off Length of Diesel Fuel Jets," SAE Technical Paper 2005-01-3843, 2005, doi:10.4271/2005-01-3843.

34. Pickett, L., Manin, J., Genzale, C., Siebers, D. et al., "Relationship Between Diesel Fuel Spray Vapor Penetration/Dispersion and Local Fuel Mixture Fraction," SAE Int. J. Engines 4(1):764-799, 2011, doi: $\underline{10.4271 / 2011-01-0686}$.

35. Pickett L.M and Siebers D.L, "Soot in Diesel Fuel Jets: Effects of Ambient Temperature, Ambient Density, and 
Injection Pressure" Combustion and Flame 138: 114-135, 2008, doi: $\underline{10.1016 / \text { j.combustflame.2004.04.006. }}$.

36. Payri, F., Pastor, J., Nerva, J., and Garcia-Oliver, J., "LiftOff Length and KL Extinction Measurements of Biodiesel and Fischer-Tropsch Fuels under Quasi-Steady Diesel Engine Conditions," SAE Int. J. Engines 4(2):2278-2297, 2011, doi: 10.4271/2011-24-0037.

37. Hann D. and Mungal M. G., "Direct Measurement of Entrainment in reacting/nonreacting Turbulent Jets" Combustion and Flame 124 (3): 370-386, 2001, doi: 10.1016/S0010-2180(00)00211-X.

38. Pickett, L., Kook S., Peerson H. and Andersson Ö, "Diesel Fuel Jet Lift-off Stabilization in the Presence of Laser-Induced Plasma Ignition", Proceedings of the Combustion Institute 32(2): 2793-2800, 2009, doi: 10.1016/i.proci.2008.06.082.

39. Manin J, Kastengren A. and Payri R., "Understanding the Acoustic Oscillations Observed in the Injection Rate of a Common-Rail Direct Injection Diesel Injector,” J. Eng. Gas Turbines Power, 134(12), 122801, 2012,(10 pages). doi: $\underline{10.1115 / 1.4007276}$.

40. Peters, N., "Turbulent Combustion", Cambridge University Press, pp. 237-261, 2000, ISBN 0-521-66082$\underline{3}$.

41. Soid S. N. and Zainal Z.A., "Spray and Combustion Characterization for Internal Combustion Engines Using Optical Measuring techniques - a review," Energy, 36 (2): 724-741, 2011, doi: 10.1016/j.energy.2010.11.022.

42. Payri, R., Salvador, F., Gimeno, J. and Bracho, G., "A New Methodology for Correcting the Signal Cumulative Phenomenon on Injection Rate Measurements," Experimental Techniques, 32: 46-49, 2008, doi: $10.1111 / \mathrm{j} .1747-1567.2007 .00188 . \mathrm{x}$

43. Payri R., García-Oliver J.M, Bardi M. and Manin J., "Fuel Temperature Influence on Diesel Sprays in Inert and Reacting conditions," Applied Thermal Engineering 35: 185-195, 2012, doi: 10.1016/i.applthermaleng.2011.10.027

44. Siebers, D., "Liquid-Phase Fuel Penetration in Diesel Sprays," SAE Technical Paper 980809, 1998, doi: $10.4271 / 980809$.

\section{CONTACT INFORMATION}

$\begin{array}{ll}\text { José V. Pastor } & \text { jpastor@mot.upv.es } \\ \text { Raúl Payri } & \text { rpayri@mot.upv.es } \\ \text { José M. García-Oliver } & \text { jgarciao@mot.upv.es } \\ \text { Francisco J. Briceño } & \text { frabris1@mot.upv.es }\end{array}$

\section{ACKNOWLEDGMENTS}

This work was partially funded by the Spanish Ministry of Education and Science through the "LES METHODS FOR THE SIMULATION OF MULTIPHASE SPRAYS" project (ENE2010-18542).

Mr. Francisco J. Briceño wishes to acknowledge financial support through a $\mathrm{PhD}$ studies grant (AP2008-02231) also sponsored by the Spanish Ministry of Education and Science.

Lastly but not least, authors would like to express their gratitude to José Enrique del Rey for his help in data acquisition, as well as in the test cell maintenance.

\section{NOMENCLATURE}

CPF constant pressure flow

PID proportional/integral/derivative control

n refractive index

k Gladstone-dale number

$\rho \quad$ gas/liquid density

$f \quad$ lens focal length

1D one dimensional

LRT Log-Likelihood Ratio Test

DL digital level

DBI diffuse back illumination

ECN engine combustion network

SOC start of combustion

ASOI after start of injection

ASOE after start of energizing

LoL lift-off length 


$\begin{array}{ll}\mathbf{K} & \text { lift-off scaling constant } \\ \mathbf{U}_{\mathbf{0}} & \text { injection velocity } \\ \mathbf{T}_{\text {air }} & \text { air temperature } \\ \mathbf{S} & \text { spray tip penetration } \\ \mathbf{t} & \text { time } \\ \mathbf{d}_{\mathbf{e q}} & \text { equivalent diameter } \\ \boldsymbol{\theta} & \text { spray cone angle } \\ \mathbf{t *} & \text { dimensionless time scales } \\ \mathbf{S} * & \text { spray dimensionless tip penetration } \\ \boldsymbol{\phi} & \text { fuel-air equivalence ratio } \\ \Delta \mathrm{P} & \text { injection pressure drop } \\ \mathbf{d}_{\mathbf{0}} & \text { nozzle diameter }\end{array}$

\section{$\underline{\text { Subscripts }}$}

$\begin{array}{ll}\text { mask } & \text { pixels above threshold } \\ \text { s } & \text { schlieren } \\ \text { OH } & \mathrm{OH}^{*} \text { chemiluminescence } \\ \text { f } & \text { fuel } \\ \text { a } & \text { air }\end{array}$

